Research Article

\title{
Gob-Side Entry Retaining Technology with Advanced Empty Hole Butterfly-Shaped Weakening in Three-Soft Coal Seam in China
}

\author{
Tao Yang $\mathbb{D}^{1,2}$ and Jie Zhang $\mathbb{D}^{1,2}$ \\ ${ }^{1} X i$ 'an University of Science and Technology, Xi'an 710054, Shaanxi, China \\ ${ }^{2}$ Key Laboratory of Western Mine Exploitation and Hazard Prevention with Ministry of Education, \\ Xi'an University of Science and Technology, Xi'an 710054, China \\ Correspondence should be addressed to Tao Yang; yangtao@xust.edu.cn
}

Received 24 October 2019; Revised 25 December 2019; Accepted 31 December 2019; Published 22 January 2020

Academic Editor: Hossein Moayedi

Copyright (C) 2020 Tao Yang and Jie Zhang. This is an open access article distributed under the Creative Commons Attribution License, which permits unrestricted use, distribution, and reproduction in any medium, provided the original work is properly cited.

\begin{abstract}
China has a large number of coal resources in "three-soft" geological conditions. The roof of these coal seams is soft and has low strength. Under this condition, gob-side entry retaining can be carried out under the guidance of roof leading holes to achieve the goal of nonblasting roof cutting and roadway retaining. In this paper, the technology of void weakening, roof cutting, and pressure relief along gob retaining roadway is investigated. The force model of void is established, and the stress concentration of void and interference effect of stress superposition between holes is simulated by COMSOL numerical simulation software. The influence of different factors on stress distribution surrounding round holes is then studied by orthogonal experiment. The results show that the distribution of the plastic zone in circular holes varies with the lateral pressure ratio. With the increase of lateral pressure ratio, the shape of the plastic zone will gradually change from circular to elliptical, and eventually to butterfly, and the size of the butterfly plastic zone is positively correlated with the aperture. On this basis, the technology of "empty hole weakening + dense pillar" roof cutting and gob-side entry retaining is presented. The methodology is then applied to an auxiliary air intake roadway of 21309 working face in the Xiangshan Mine. Industrial testing of three-soft seams using advanced empty hole without blasting roof cutting and gob-side entry retaining is then successfully carried out. The advanced weakening hole replaces the original blasting cutting technology, omits the blasting cutting link in the existing gob-side entry retaining technology, shortens the retaining time, solves the problems such as large coal dust concentration and bad construction environment in the blasting process, and provides scientific theoretical basis for the gob-side entry retaining technology without blasting under such geological conditions.
\end{abstract}

\section{Introduction}

Efficient mining practices are becoming increasingly important as global coal market competition rises. Emerging mining techniques that do not require coal pillar are of great significance for improving resource recovery, reducing roadway heading and mining costs, and enhancing mine production safety [1-4]. Promoting mining techniques without coal pillar is therefore vital for the technical transformation of production mines, the alleviation of mining relations, and mine life extension. Furthermore, it is also an important way for coal enterprises to improve safety conditions and technical and economic indicators, increase production, and reduce losses [5]. Two key technologies currently exist to control the mine pressure of gob-side entry retaining. The first is blasting roof cutting and pressure relief and the second is gob filling and bearing technology. In the process of blasting roof cutting, the leading working face adopts the blasting method along the roof edge of gob-side entry retaining to make cracks appear inside the roof. Due to the leading supporting pressure of the working face, the cracks are then connected. After the working face is completed, the roof of the gob is cut off along the cracks under the loading of overlying strata to ensure the integrity of the roof [6]. Blasting roof cutting can be utilized for the retained gob-side entry; however, it is dangerous to carry out blasting in the limited underground space. The blasting process also produces a large amount of coal dust, which is not only bad 
for the health of the workers but also deteriorates the working environment. As inflammable gases are present in the mine, blasting technology poses a potential threat to mine production safety [7]. Alternatively, gob filling and bearing technology works to install backfilling materials in the gob to bear the loading of overlying strata. As a result, the gob roof is cut off along the edge of the backfill body which can effectively control the deformation and failure of the gob-side entry retaining roof. However, the amount of backfill engineering in this process is huge, requiring a large amount of manpower and material resources which increase the cost of gob-side entry retaining [8-11].

To solve the problems of complicated construction technology and the high cost of gob-side entry retaining, a new gob-side entry retaining method of roof cutting and pressure relief was proposed by researchers including $\mathrm{He}$ Manchao $[12,13]$. By presplit blasting of the roof, the basic roof of the lower part of the caving side is indirectly transformed into immediate caving. The broken gangues after cutting then provide support for the overlying strata, limiting its rotational deformation and reducing the impact loading of roof fracture $[14,15]$. By analyzing the characteristics of strata behavior of gob-side entry retaining with direct thick and hard roof in a coal mine over $1000 \mathrm{~m}$ deep, structural optimization technology of overlying strata for gob-side entry retaining with hard roof conditions has also been proposed [16], which is combined with roof caving optimization to advance the working face and pressure relief for hanging roof structure cutting along the gob side using deep-hole presplitting blasting. By analyzing the deformation, stress, and structure states of roadway surrounding rock reparation in deep gob-side entry retaining, Qiao et al. put forward the concept of "critical structure between instability and stability" of gob-side entry retaining reparation [17]. Reasonable repairing time and construction process were also determined, and an initiative-passive collaborative supporting system was proposed. Based on the analysis of the stress state of a roof in the process of mining, researchers determined the presplitting cutting height of roof, presplitting cutting angle, and distance between presplitting blasting holes as the key parameters for the analysis of the stress state of the roof. Using self-developed loading test equipment, researchers carried out a study on the dynamic evolution law of floor fracture and floor fractal dimensions in the excavation period, the first mining influenced period, the roadway retaining period, and the second mining influenced period. The relation between floor fractal dimension and floor heave was then obtained according to fractal geometry theory. Researchers expounded the zone characteristics of shallow-hole blasting and presented the corresponding calculation formulas. The mechanical model of the cutting roof of the hard roof along the gob was also established, and the formula of cutting roof resistance of the roadside backfill was given under blasting cutting of the direct roof $[18,19]$. The above scholars used theoretical analysis and numerical simulation to study the technology of gob-side entry retaining formed by roof cutting and pressure relief in thin coal seam. The relationship between the roof loading of retaining roadway and the cantilever length of gob roof was analyzed, the mechanical model of the cutting roof was established, and parameters of presplit blasting roof cutting were obtained. The blasting technique was used to perform forced pressure relief on the gob-side entry retaining roof in most studies, and the stress transfer between the roof of the roadway and the roof of the gob was cut off to achieve the roof cutting [20-22]. The hard roof presplitting blasting pressure relief technology of roof cutting along gob can guide the roadway roof and gob roof to cut off along the crack produced by blasting and reduce the resistance [23, 24]. However, in coal seam with "three-soft" characteristics, the roadway retaining roof is soft rock. In the process of stoping, the roof can easily be broken under leading stress [25]. It must therefore be determined if automatic pressure relief can be realized under the guidance of leading holes [26-28]. A model of empty hole weakening in gob-side entry retaining is provided in Figure 1.

China has a large number of coal resources in the "threesoft" geological condition [29]. The roof of these coal seams is soft and has low strength [30]. It can be cut off along the edge of the gob under the combined action of "self-gravity + empty hole weakening + roadside support," making it possible to optimize the technique of nonblasting gob-side entry retaining. Upgrading and optimizing the technology of gobside entry soft roof retaining is aimed at reducing mining costs, simplifying the construction process, and improving the operating environment and is therefore of great significance for mining under such geological conditions.

\section{Engineering Background}

2.1. Geological Conditions. The 21309 working face of No. 3 coal seam in Xiangshan Mine is studied in this paper. The fully mechanized mine working face is located in the middle of the mining area, with a working face length of $210 \mathrm{~m}$. The roadway is arranged along a coal seam strike, its channel length is $1171.6 \mathrm{~m}$, and the buried depth is $320 \mathrm{~m}$. The auxiliary air roadway is mined using the roadway retaining formed by roof cutting and pressure relief technology. The east section is adjacent to the gob of the 21308 fully mechanized mining working face, the southern section is bounded by major faults with a drop greater than $10 \mathrm{~m}$, the western section is adjacent to the 21310 fully mechanized mining working face, and the northern section is bounded by the protective coal pillars of Hongqiqu.

2.1.1. Coal Seam. The No. 3 coal seam contains semibright coal which is dominated by bright coal with a middle mirror and thin strip of dark coal. The structure of the coal seam is simple, and the lower part of the coal seam contains gangues with the thickness of $0.1 \sim 0.2 \mathrm{~m}$ and bottom thick powder seam of $0.2 \sim 0.3 \mathrm{~m}$. The coal seam thickness of the two roadways in the working face is between $0.8 \mathrm{~m}$ and $3.55 \mathrm{~m}$, with an average thickness of $2.1 \mathrm{~m}$, which is a relatively stable medium-thick coal seam. The No. 3 coal mine contains meagre coal. According to the coal seam outcrop and drilling data, the coal ash content of the working face is $25 \sim 40 \%$, and its sulfur content is approximately $0.5 \%$. 


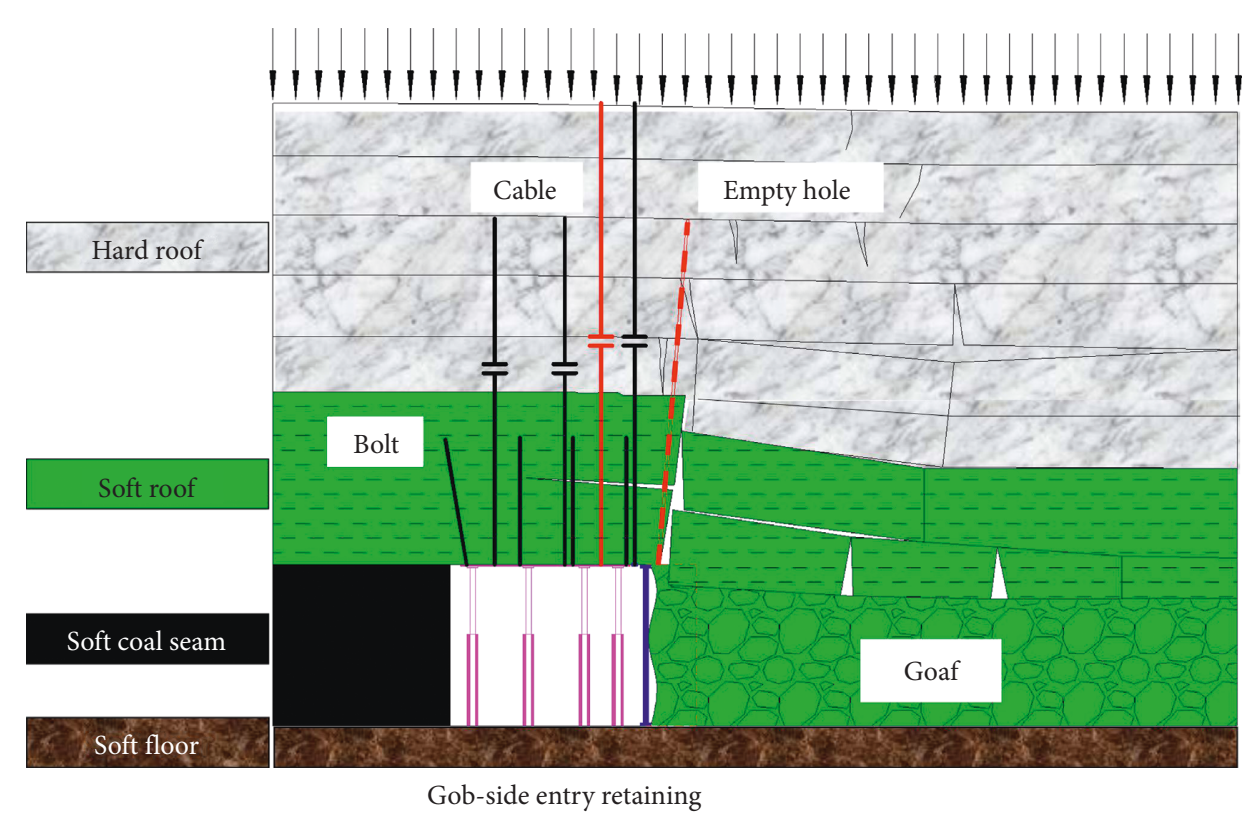

FIGURE 1: Model of empty hole weakening in gob-side entry retaining.

2.1.2. Soft Roof. The soft roof is composed of black or grey medium-thick silty mudstone, siltstone, and fine-grained sandstone. The materials are calcium-argillaceous cemented and contain subordinate mica flakes. The average thickness of the soft roof is $5 \mathrm{~m}$.

2.1.3. Hard Roof. The hard roof is composed of hard siltstone, fine-grained sandstone, and medium-sandstone with horizontal bedding. The materials are argillaceous cemented and contain subordinate mica flakes. There are complete fossil leaves at the bottom, and its thickness varies from 4.5 to $6.0 \mathrm{~m}$, with average thickness of $5.0 \mathrm{~m}$.

2.1.4. Soft Floor. The oblique floor of the working face is not developed, and the floor consists of grey siltstone which is argillaceous cemented and is in the thick layer. There are complete fossil plant roots, and its thickness varies from 3.8 to $5.2 \mathrm{~m}$, with average thickness of $4.2 \mathrm{~m}$. The mechanical parameters of the 21309 fully mechanized mining working face are provided in Table 1.

2.2. Main Problems. Field surveying determines that roof collapse is not sufficient after the previous blasting roof cutting. The roof loading of gob is transferred to the roadway support body, which causes complete deformation or even fracture of the roadway support body, seriously threatening the safe use of the roadway (Figure 2). Therefore, studying the parameters of empty hole weakening and the damage mechanism of the rocks based on the existing technology of gob-side entry retaining is required to provide a theoretical basis for optimizing the roadway retaining technology.

In "three-soft" coal seam, the existing blasting roof cutting and roadway retaining technology is replaced by the roof cutting technology of empty hole weakening to improve the recovery rate, reduce the amount of roadway driving, improve the working environment, and reduce retaining roadway costs. A schematic diagram of roadway retaining is shown in Figure 3. In the process of gob-side entry retaining formed by roof cutting and pressure relief, the surrounding rock deformation will undergo three stages: the initial stage, the roof cutting stage, and the stable stage. At the initial stage, the roof of the working face is small-area exposed, and the basic roof rock has not reached the limit of breaking distance. At this time, the loading of overlying strata on the working surface is mainly undertaken by the basic roof, as shown in Figure 3(a). As the working face advances, the overburden roof area increases accordingly and the key blocks near the upper part of roadway retaining rotate and sink to the caving side along the fracture line of overlying rock beam. With the increase of rotation angle, the support strength of the roadside support structure increases. When the key block reaches the maximum bending moment on the upper side of the roadside support structure, the overlying basic roof cracks, as shown in Figure 3(b). This stage is an important link in roof cutting and roadway retaining, and the support body needs to provide larger support force to cut off the roof. After the basic roof is cut off, the overburden rock is carried by the caving gangues, the roadside support, and the coal side, assisting the overburden rock to regain balance and maintain the stability of the surrounding rock. The upper strata tends to be stable due to contact with gangues, as shown in Figure 3(c).

\section{Simulation Test Analysis}

\subsection{Single-Hole Stress Distribution Model}

3.1.1. Theoretical Analysis of Borehole Stress Distribution. For a single hole with inner radius $r$ and outer radius $R$, there are internal pressure $q_{1}$ and external pressure $q_{2}$, and its stress distribution is symmetrical, as shown in Figure 4. 
TABLe 1: Physical and mechanical parameters of rock mass.

\begin{tabular}{|c|c|c|c|c|c|c|c|}
\hline Lithology & $\begin{array}{l}\text { Bulk weight } \\
\left(\mathrm{kN} / \mathrm{m}^{3}\right)\end{array}$ & $\begin{array}{c}\text { Compressive } \\
\text { strength }(\mathrm{MPa})\end{array}$ & $\begin{array}{c}\text { Tensile } \\
\text { strength } \\
(\mathrm{MPa})\end{array}$ & $\begin{array}{c}\text { Elastic } \\
\text { modulus } \\
(\mathrm{MPa})\end{array}$ & $\begin{array}{c}\text { Cohesion } \\
(\mathrm{MPa})\end{array}$ & $\begin{array}{c}\text { Internal } \\
\text { friction angle } \\
\left({ }^{\circ}\right)\end{array}$ & $\begin{array}{c}\text { Poisson's } \\
\text { ratio } v\end{array}$ \\
\hline Siltstone & 26.7 & 39.3 & 3.12 & $3.0 \times 10^{4}$ & 6.5 & 33 & 0.22 \\
\hline $\begin{array}{l}\text { Argillaceous } \\
\text { siltstone }\end{array}$ & 26.6 & 34.8 & 3.72 & $3.1 \times 10^{4}$ & 5.7 & 38 & 0.16 \\
\hline No. 3 coal seam & 13.8 & 7.9 & 0.39 & $0.5 \times 10^{4}$ & 1. 7 & 31 & 0.24 \\
\hline Siltstone & 26.1 & 21.0 & 1.15 & $1.4 \times 10^{4}$ & 3.5 & 35 & 0.20 \\
\hline $\begin{array}{l}\text { Next slice of no. } 3 \\
\text { coal seam }\end{array}$ & 13.6 & 7.5 & 0.31 & $0.5 \times 10^{4}$ & 1.6 & 31 & 0.23 \\
\hline Siltstone & 24.9 & 30.3 & 2.65 & $3.4 \times 10^{4}$ & 3.6 & 30 & 0.22 \\
\hline
\end{tabular}

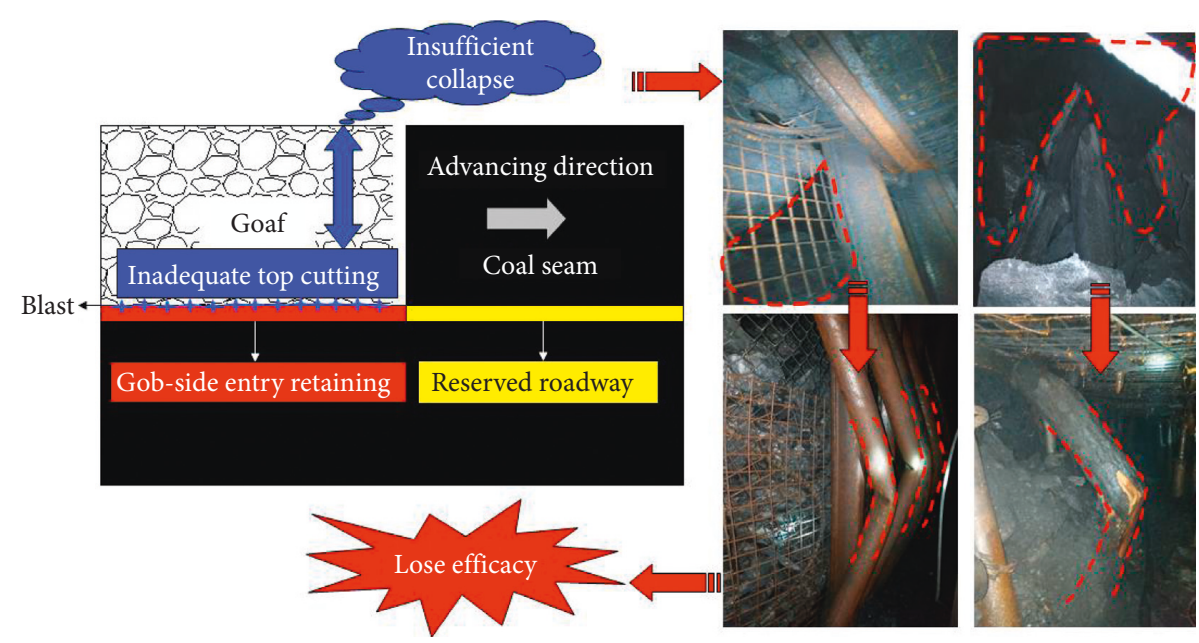

Figure 2: Schematic diagram of blasting roof cutting and roadway retaining.

Stress component expressions are as follows:

$$
\left.\begin{array}{l}
\sigma_{\rho}=\frac{A}{\rho^{2}}+B(1+2 \ln \rho)+2 C \\
\sigma_{\varphi}=-\frac{A}{\rho^{2}}+B(3+2 \ln \rho)+2 C \\
\tau_{\rho \varphi}=\tau_{\rho \varphi}=0
\end{array}\right\},
$$

where $\sigma_{\rho}$ is radial stress, $\sigma_{\varphi}$ is tangential stress, $\tau_{\rho \varphi}$ is shear stress, and $A, B$, and $C$ are the arbitrary constants.

The internal and external stress boundary states must meet the following conditions:

$$
\left.\begin{array}{c}
\frac{A}{r^{2}}+B(1+2 \ln r)+2 C=-q_{1} \\
\frac{A}{R^{2}}+B(1+2 \ln r)+2 C=-q_{2}
\end{array}\right\} .
$$

By displacement single value condition $B=0, A$ and $C$ can be obtained through substitution into equation (2):

$$
\left.\begin{array}{l}
A=\frac{r^{2} R^{2}\left(q_{2}-q_{1}\right)}{R^{2}-r^{2}} \\
C=\frac{q_{1} r^{2}-q_{2} R^{2}}{2\left(R^{2}-r^{2}\right)}
\end{array}\right\} .
$$

The Lame solution with single hole under uniform pressure can be obtained by substituting equation (3) into equation (1):

$$
\left.\begin{array}{c}
\sigma_{\rho}=-\frac{\left(R^{2} / \rho^{2}\right)-1}{\left(R^{2} / r^{2}\right)-1} q_{1}-\frac{1-\left(r^{2} / \rho^{2}\right)}{1-\left(r^{2} / R^{2}\right)} q_{2} \\
\sigma_{\varphi}=-\frac{\left(R^{2} / \rho^{2}\right)+1}{\left(R^{2} / r^{2}\right)-1} q_{1}-\frac{1+\left(r^{2} / \rho^{2}\right)}{1-\left(r^{2} / R^{2}\right)} q_{2}
\end{array}\right\} .
$$

For the roof weakening holes, the inner wall of the hole is free surface and there is only external pressure $q_{2}, q_{1}=0$. Therefore, equation (4) can be simplified into

$$
\left.\begin{array}{l}
\sigma_{\rho}=-\frac{1-\left(r^{2} / \rho^{2}\right)}{1-\left(r^{2} / R^{2}\right)} q_{2} \\
\sigma_{\varphi}=-\frac{1+\left(r^{2} / \rho^{2}\right)}{1-\left(r^{2} / R^{2}\right)} q_{2}
\end{array}\right\} .
$$

Roof weakening holes are located deep underground with small diameters. The drilling radius is smaller than the size of the immediate roof, so the roof can be regarded as an infinite elastomer, and $q_{2}$ is caused by in situ stress $q_{2}=\lambda \gamma H$. Therefore, equation (5) can be simplified as follows: 


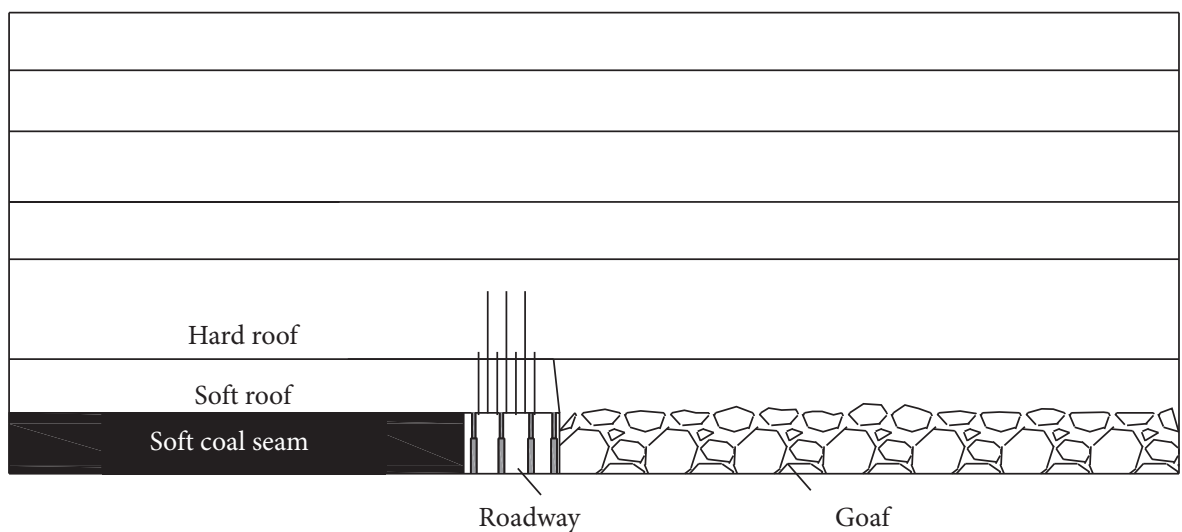

(a)

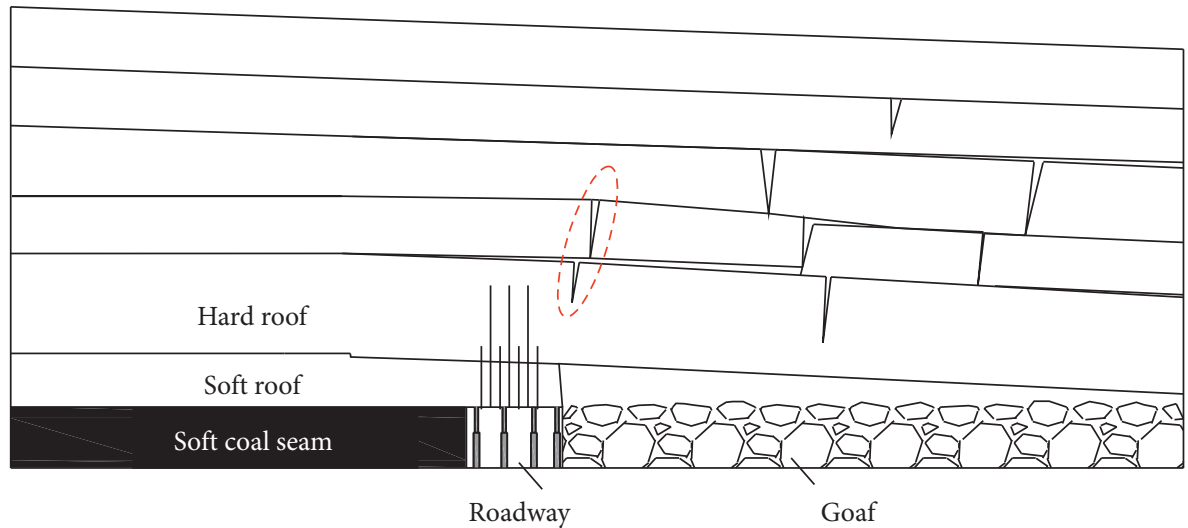

(b)

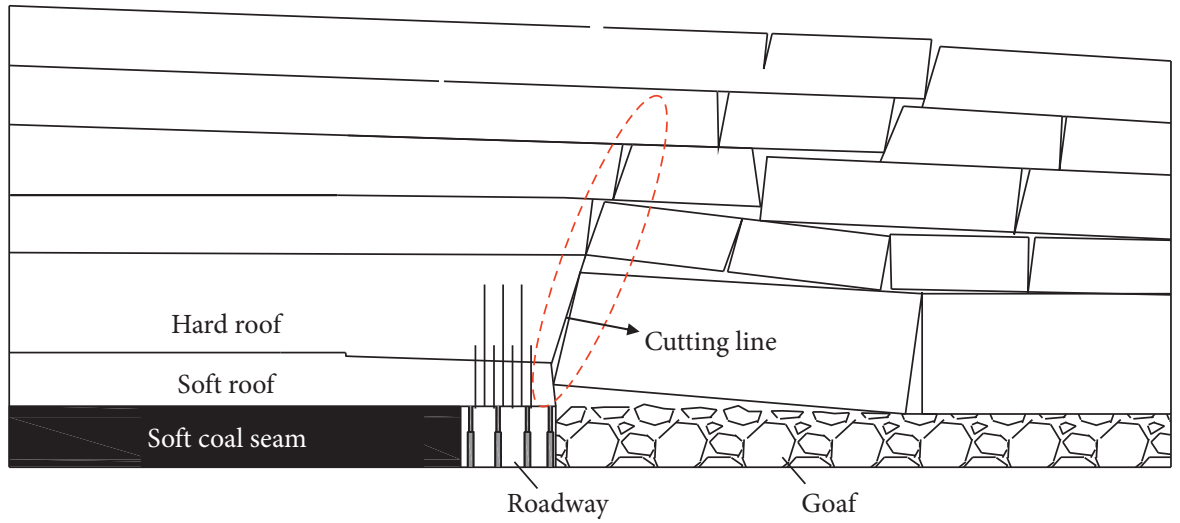

(c)

FIgURE 3: Strata structures of roof in different stages: (a) initial stage, (b) roof cutting stage, and (c) stable stage.

$$
\left.\begin{array}{c}
\sigma_{\rho}=-\left(1-\frac{r^{2}}{\rho^{2}}\right) \lambda \gamma H \\
\sigma_{\varphi}=-\left(1+\frac{r^{2}}{\rho^{2}}\right) \lambda \gamma H
\end{array}\right\} .
$$

where $\lambda$ is the lateral pressure coefficient in which $\lambda=v /(1-v), v$ is Poisson's ratio, $\gamma$ is the bulk density of overlying strata $\mathrm{N} / \mathrm{m}^{3}$, and $H$ is the buried depth $\mathrm{m}$.

The following conclusions can be drawn: (i) In the stress field of uniformly distributed loading, the entire periphery of the round hole is in the state of compression stress

(ii) The stress is independent of the elastic constants $E$ and $\mu$

(iii) The distribution of principal stress $\left(\sigma_{\rho}, \sigma_{\varphi}\right)$ is independent of the angle

3.1.2. Numerical Simulation of Stress Distribution in Single Hole. In order to directly analyze the stress distribution around the single hole, COMSOL numerical simulation 


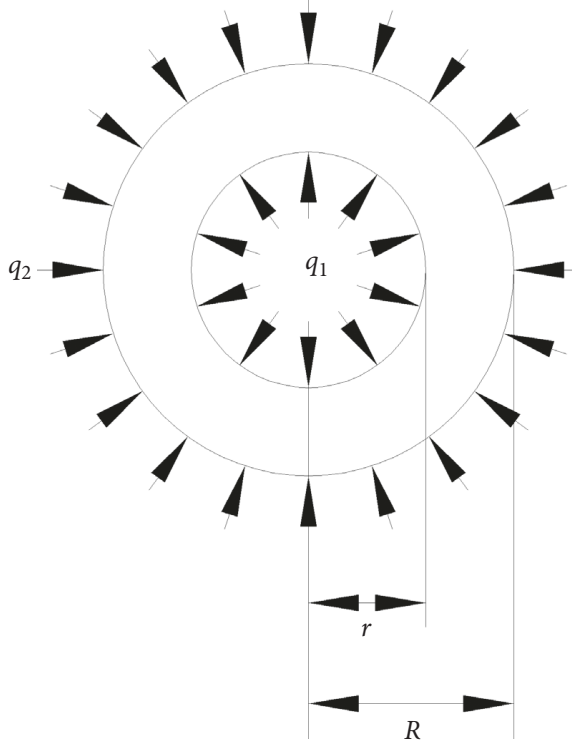

FIGURE 4: Stress distribution under uniformly distributed loading in a single hole.

software was used to simulate the stress distribution of the single hole in thin plate based on the strata of immediate roof in the working face return air laneway 12309 in Xiangshan coal mine. A schematic diagram of the simulation scheme is provided in Figure 5. The side length of the square thin plate is $80 \mathrm{~cm}$, the diameter of the single hole is $2 \mathrm{~cm}$, compressive stress $P_{1}=1 \mathrm{MPa}$ is applied in the $x$-axis, and the compressive stress $P_{2}=2 \mathrm{MPa}$ is applied to the $y$-axis. The simulation results are shown in Figure 6 [31-33].

As illustrated in Figure 6, under bidirectional unequal pressure, stress concentration is obvious around the single hole along the $x$-axis, while the stress releasing zone appears around the single hole along the $y$-axis. The maximum stress is $4.40 \mathrm{MPa}$, the minimum stress is $0.50 \mathrm{MPa}$, and the stress is distributed symmetrically along the $x$-axis and the $y$-axis. The stress concentrating zone and the stress releasing zone are distributed around the hole wall within one diameter, and the stress does not change significantly beyond this range.

3.2. Stress Distribution Model of Double Holes. According to the attenuation of tangential stress around the single hole, the range of surrounding severe influence is generally bounded at $5 \%$ above the in situ stress. The influence radius is $L$, and if the spacing between two adjacent holes is greater than $2 L$, the two holes will not affect each other. As a result, the stress distribution around the adjacent holes will essentially be the same as that of the single hole. In this case, even if there are multiple boreholes, they do not affect each other. Conversely, if the spacing between two holes is less than $2 L$, they will have an effect on each other.

Stress distribution around the double holes was simulated in this paper, and a schematic diagram of the simulation scheme is shown in Figure 7 [34-36]. The size of rectangular thin plate is $80 \mathrm{~cm}$ (length) $\times 80 \mathrm{~cm}$ (width) and its aperture $D$ is $2 \mathrm{~cm}$, with compressive stress $P_{1}=1 \mathrm{MPa}$ in

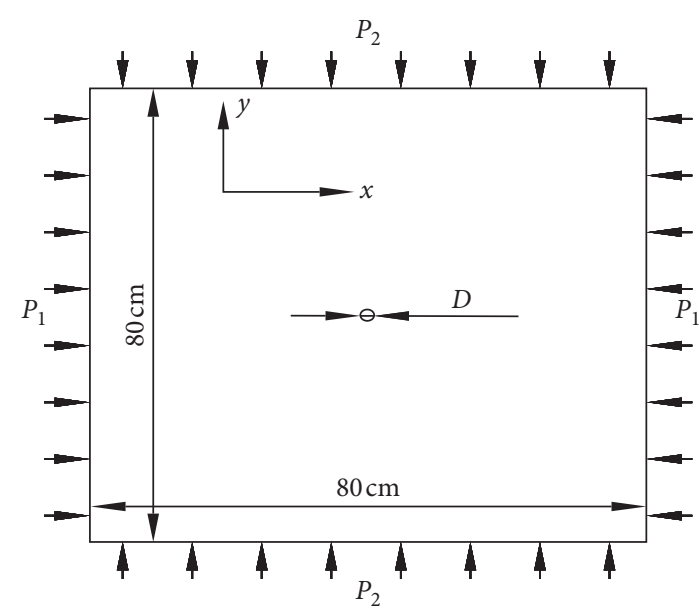

Figure 5: Stress model and mesh generation of single hole.

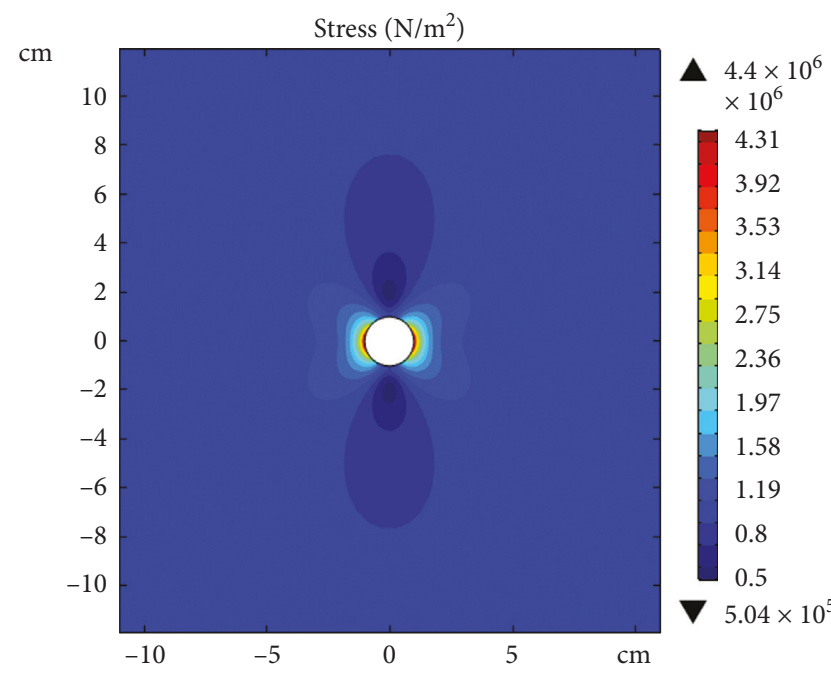

FIgURE 6: Stress distribution of single hole.

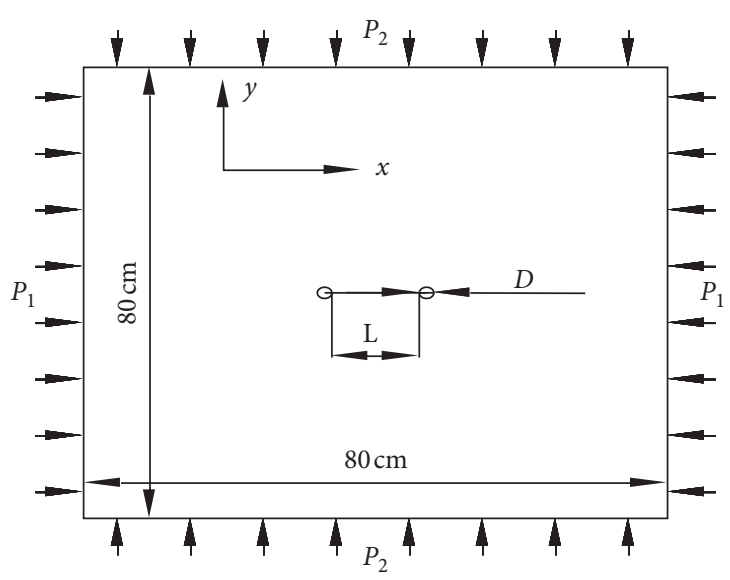

Figure 7: Stress model and mesh generation of double holes.

the $x$-axis and compressive stress $P_{2}=2 \mathrm{MPa}$ in the $y$-axis. The stress distribution of thin plate was simulated with hole spacing $L=0.5 D, L=1 D, L=2 D, L=3 D, L=4 D$, and $L=5 D$, respectively. Stress distribution results are shown in Figure 8, 


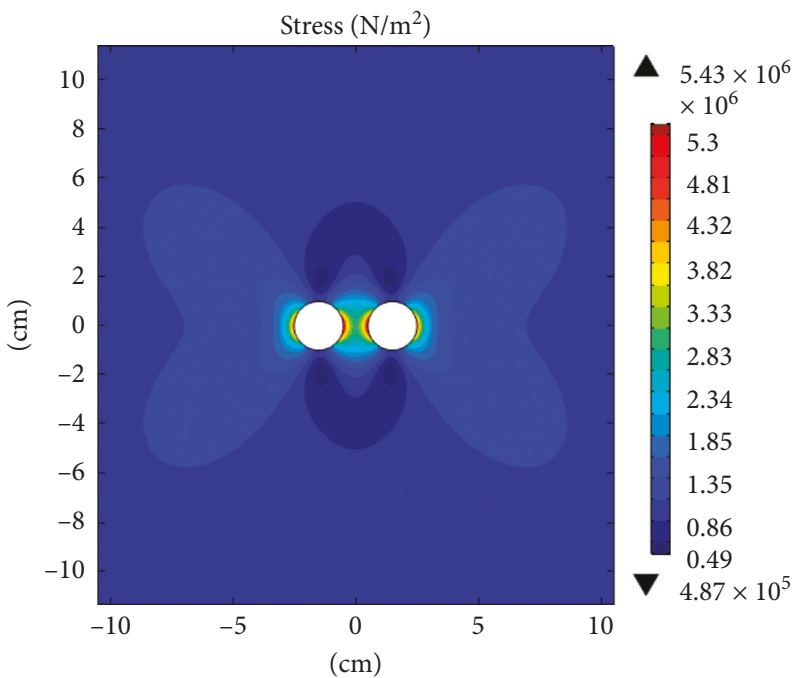

(a)

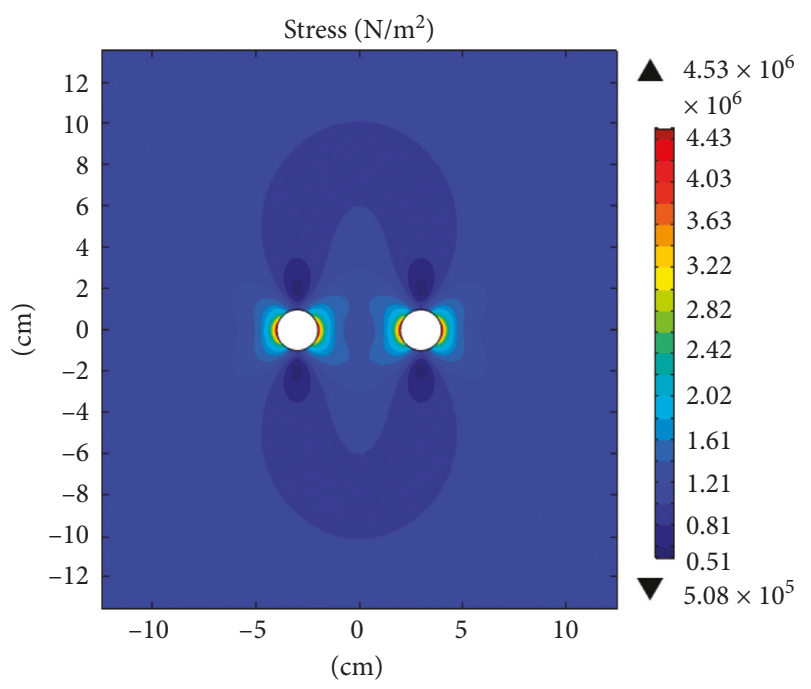

(c)

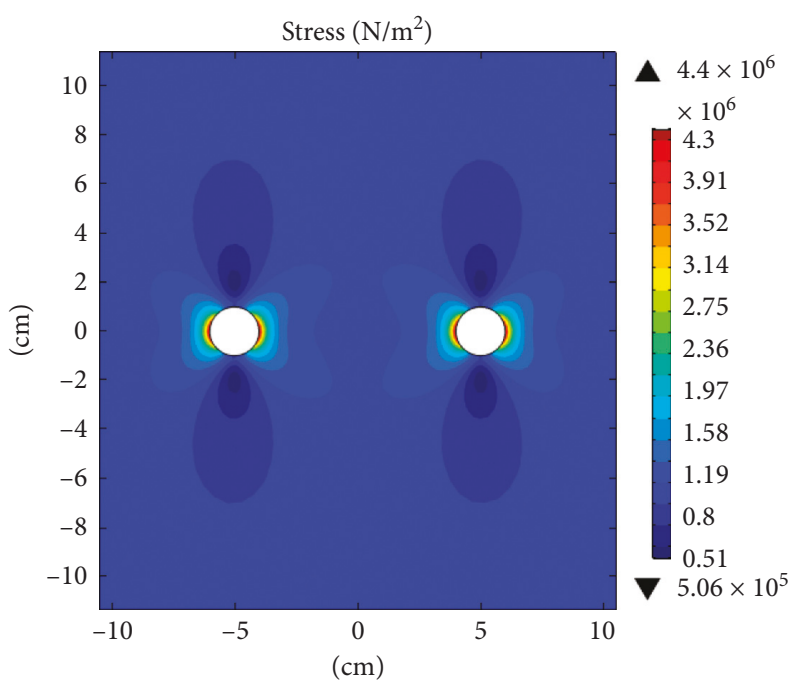

(e)

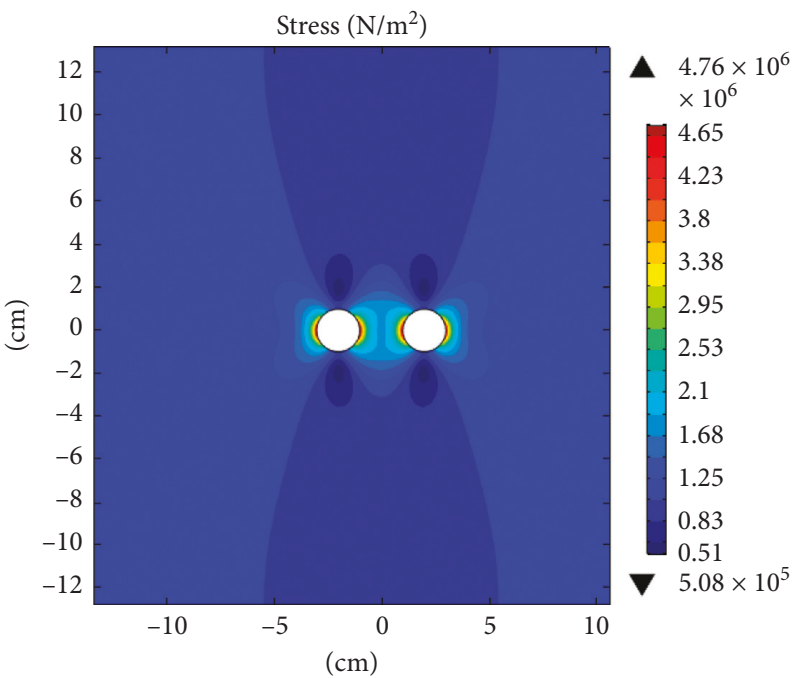

(b)

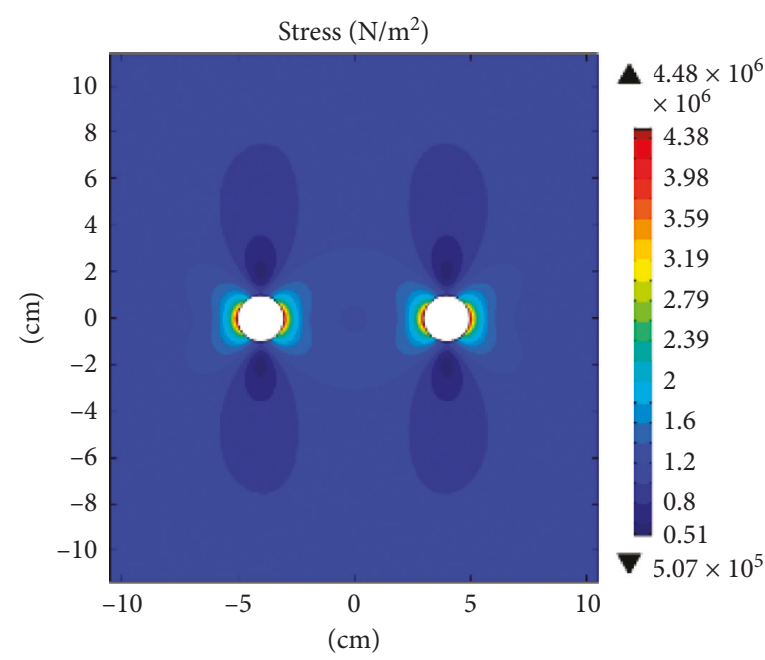

(d)

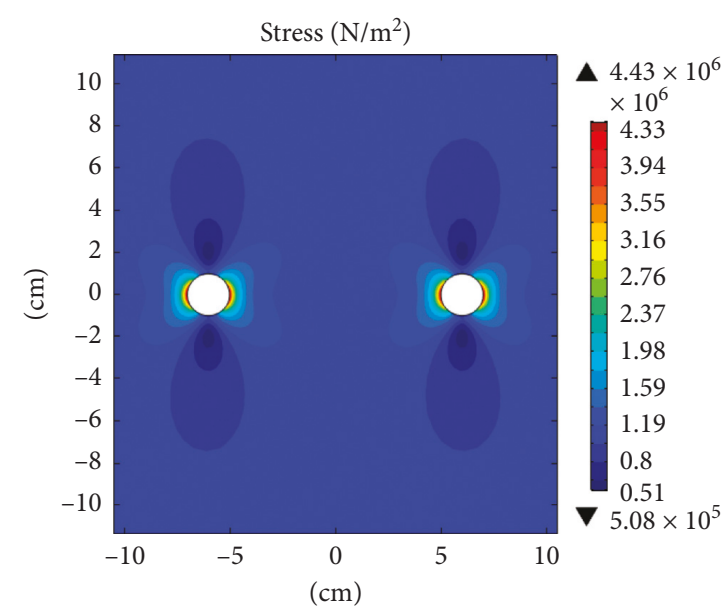

(f)

Figure 8: Stress distribution at different hole spacings: (a) $L=0.5 D$; (b) $L=1 D$; (c) $L=2 D$; (d) $L=3 D$; (e) $L=4 D$; (f) $L=5 D$. 
the extreme values of stresses at different distances are summarized in Table 2, and the stress curve is shown in Figure 9.

As illustrated in Figure 8, similar to single hole, under bidirectional unequal pressure, low stress zone and high stress zone also exist around the double holes. When hole spacing $L=0.5 D$, the stress increases obviously in the area between the two holes. Moreover, the stress contours around the two holes are superimposed through each other and a stress superposition zone is formed around the two holes. The maximum stress after superposition is $5.43 \mathrm{MPa}$ and the minimum stress is $0.49 \mathrm{MPa}$. Unlike a single hole, the maximum stress along the line of the center of the two holes does not appear on the left and right sides of the hole wall at the same time. The maximum stress is caused by the superposition of the stress between the two holes and appears on the hole wall between the two holes and not on the lateral wall. When hole spacing $L=1 D$, the stress superposition between the two holes is still obvious. Compared with $L=0.5 D$, the stress superposition is restrained, and the maximum stress is still located at the hole wall connected by the center of the two holes. At this time, the maximum stress is $4.76 \mathrm{MPa}$ and the minimum stress is $0.51 \mathrm{MPa}$. When hole spacing $L=2 D$, the maximum stress of the hole wall is $4.53 \mathrm{MPa}$ and the minimum stress is $0.51 \mathrm{MPa}$, when hole spacing $L=3 D$, the maximum stress of the hole wall is $4.48 \mathrm{MPa}$ and the minimum stress is $0.51 \mathrm{MPa}$, and when hole spacing $L=4 D$, the maximum stress of the hole wall is $4.40 \mathrm{MPa}$ and the minimum stress is $0.51 \mathrm{MPa}$. Finally, when hole spacing $L=5 D$, it is the same as $L=4 D$.

As shown in Figure 9, for single hole, the stress decreases along the horizontal direction from the hole wall. It changes sharply in the range of $1 \mathrm{~cm}$ away from the hole wall. In the range of $2-4 \mathrm{~cm}$, the rate of stress change gradually decreases, while the stress is almost equal at a distance of $4 \mathrm{~cm}$ away from the hole wall. For double holes, the regional stress between the two holes increases from the midpoint to both sides and is distributed symmetrically. The stress superposition is more obvious when the hole spacing decreases, while stress superposition weakens when the hole spacing increases. When hole spacing $L \geq 4 D$, the minimum stress is almost equal to that of a single hole, indicating that the two holes no longer interfere with each other.

\subsection{Analysis of Influencing Factors of Stress Interference in Empty Hole}

3.3.1. Orthogonal Test Design. To analyze the influencing factors of the stress interference between the two holes, the lateral pressure ratio $\eta\left(\eta=P_{2} / P_{1}\right)$ is introduced. This ratio mainly explores the effect of loading $P$, diameter $D$, hole spacing $L$, and lateral pressure ratio $\eta$ on the superposition of stress interference. $P_{1}$ is taken as $1 \mathrm{MPa}, 2 \mathrm{MPa}$, and $3 \mathrm{MPa}$, with $D$ of $1 \mathrm{~cm}, 2 \mathrm{~cm}, 4 \mathrm{~cm}$, and $6 \mathrm{~cm}, L / D$ of $3,3.5$, and 4 , and $\eta$ of 1,3 , and 5 , respectively. Subscript $K$ is the ratio of the absolute value of the difference between the maximum stress $\sigma_{1}$ after the interference superposition and the maximum stress $\sigma_{2}$ at the corresponding single hole to the maximum stress $\sigma_{2}$ at the single hole. Additionally, $\alpha_{1}$ and $\alpha_{2}$ are stress concentration coefficients of double hole and single hole, respectively. Orthogonal testing was used in this study, and the test design and results are shown in Table 3.

\subsubsection{Test Results}

(1) Effect of Hole Spacing on Stress Superposition Interference between Two Holes. Orthogonal test schemes 1, 2, and 3 were selected. When $P_{1}=1 \mathrm{MPa}, \eta=1, D=1 \mathrm{~cm}$, and $L$ is $3 D$, $3.5 D$, and $4 D$, the change curve of the stress between the two holes and the corresponding single hole stress is shown in Figure 10.

The variation trend of the stress concentration coefficient after drilling illustrates that the stress concentration coefficient $\alpha 1$ in double hole is generally larger than the stress concentration coefficient 2 in single hole, and the stress concentration coefficients in both states are above 4 . As can be seen in Figure 10, with the increase of $L / D$, the stress distribution between holes is gradually consistent with that of single hole. As $\mathrm{L} / \mathrm{D}$ decreases, the minimum stress between the two holes increases, that is, the stress interference is more obvious when the hole spacing is smaller. When $L / D$ is greater than $3.5, K$ decreases significantly; meanwhile, the minimum stress between the two holes is almost equal to the minimum stress of single hole. Therefore, when the hole spacing $L / D$ is greater than 3.5 , the stress between the two holes will no longer interfere. In this case, the two holes can be considered as two independent single holes.

(2) Effect of Aperture D on Stress Superposition Interference between Two Holes. Orthogonal test schemes 4, 5, and 6 were selected. The change curve of the stress between the two holes and the corresponding single hole stress when $P_{1}=1 \mathrm{MPa}, \eta=1, L / D=3$, and $D$ is $1 \mathrm{~cm}, 4 \mathrm{~cm}$, and $6 \mathrm{~cm}$ is shown in Figure 11.

When the pore diameter $D$ is $1 \mathrm{~cm}, 4 \mathrm{~cm}$, and $6 \mathrm{~cm}$, the stress concentration coefficients in single hole are 4.43, 4.45, and 4.48 , respectively, while the stress concentration coefficients of the two holes are 4.60, 4.60, and 4.65, respectively. The results show that the stress concentration is more obvious with the increase of pore diameter. For double holes, the stress interference coefficients of $1 \mathrm{~cm}, 4 \mathrm{~cm}$, and $6 \mathrm{~cm}$ are $3.95 \%, 3.93 \%$, and $3.91 \%$, respectively, indicating that the stress interference between the two holes is barely affected by the size of the aperture.

(3) The Effect of Lateral Pressure Ratio $\eta$ on Stress Superposition Interference between Two Holes. Orthogonal test schemes 7, 8, and 9 were selected. When $P_{1}=1 \mathrm{MPa}$, $D=4 \mathrm{~cm}, L / D=3$, and $\eta$ is 1,3 , and 5 , the change curve of the stress between the two holes and the corresponding single hole stress is shown in Figure 12.

When $\eta$ is 1,3 , and 5 , the maximum stress concentration coefficients of single hole are 4.45, 3.70, and 3.95, respectively, while the maximum stress concentration coefficients of double holes are 4.63,3.75, and 4.01, respectively. With the change of lateral pressure ratio, the stress concentration 
TABLE 2: Extreme values of stresses at different hole spacings.

\begin{tabular}{lccccccc}
\hline Hole spacing $(L / \mathrm{cm})$ & Single hole & $L=0.5 D$ & $L=1.0 D$ & $L=2.0 D$ & $L=3.0 D$ & $L=4.0 D$ & $L=5.0 D$ \\
\hline Maximum stress $(\mathrm{MPa})$ & 4.40 & 5.43 & 4.76 & 4.53 & 4.48 & 4.40 & 4.40 \\
Minimum stress $(\mathrm{MPa})$ & 0.51 & 0.49 & 0.51 & 0.51 & 0.51 & 0.51 & 0.51 \\
\hline
\end{tabular}

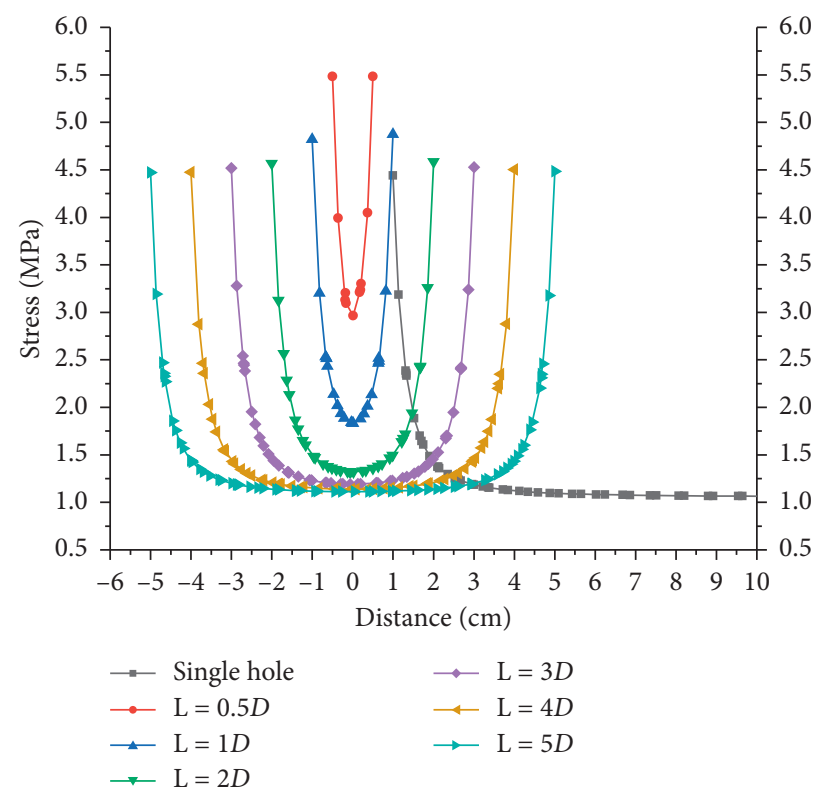

FIGURE 9: Stress distribution curve between double holes.

TABLE 3: Orthogonal test table of stress interference factors.

\begin{tabular}{|c|c|c|c|c|c|c|c|c|c|}
\hline Scheme & Factor $1 P_{1}(\mathrm{MPa})$ & Factor $2 \eta$ & Factor $3 D(\mathrm{~cm})$ & Factor $4 L / D$ & $\sigma_{1}(\mathrm{MPa})$ & $\sigma_{2}(\mathrm{MPa})$ & $K=\left|\sigma_{1}-\sigma_{2}\right| / \sigma_{2}(\%)$ & 1 & 2 \\
\hline 1 & & & & 3.0 & 1.84 & & 3.95 & 4.60 & 4.43 \\
\hline 2 & 1 & 1 & 1 & 3.5 & 1.83 & 1.77 & 3.39 & 4.58 & 4.43 \\
\hline 3 & & & & 4.0 & 1.82 & & 2.82 & 4.55 & 4.43 \\
\hline 4 & & & 1 & & 1.84 & 1.77 & 3.95 & 4.60 & 4.43 \\
\hline 5 & 1 & 1 & 4 & 3.0 & 1.85 & 1.78 & 3.93 & 4.63 & 4.45 \\
\hline 6 & & & 6 & & 1.86 & 1.79 & 3.91 & 4.65 & 4.48 \\
\hline 7 & 1 & 1 & & & 1.85 & 1.78 & 3.93 & 4.63 & 4.45 \\
\hline 8 & & 3 & 4 & 3.0 & 7.16 & 7.06 & 1.42 & 3.75 & 3.70 \\
\hline 9 & & 5 & & & 12.5 & 12.3 & 1.63 & 4.01 & 3.95 \\
\hline 10 & 1 & & & & 7.11 & 7.03 & 1.14 & 3.72 & 3.68 \\
\hline 11 & 2 & 3 & 2 & 3.0 & 14.2 & 14.1 & 0.71 & 3.72 & 3.69 \\
\hline 12 & 3 & & & & 21.3 & 21.1 & 0.95 & 3.72 & 3.69 \\
\hline
\end{tabular}

coefficient fluctuates obviously. When $\eta$ is 1 , the stress concentration will be more obvious under bidirectional isobaric. For double holes, when $\eta$ is 1,3 , and 5, stress interference factors are $3.93 \%, 1.42 \%$, and $1.63 \%$, respectively. The results show that when the lateral pressure ratio is 1 , that is, $P_{1}=P_{2}$, the superposition of stress between the two holes is more obvious.

(4) The Effect of Loading on Stress Superposition Interference between Two Holes. Orthogonal test schemes 10, 11, and 12 were selected. When $\eta=2, D=4 \mathrm{~cm}, L / D=3$, and $P_{1}$ is 1,2 , and 3 , the change curve of the stress between the two holes and the corresponding single hole stress is shown in Figure 13.

When $P_{1}$ is 1,2 , and 3 , the maximum stress concentration coefficients of single hole are 3.68, 3.69, and 3.69, respectively, while the maximum stress concentration coefficients of double holes are 3.72. With the increase of $P_{1}$, the stress concentration does not change significantly, indicating that the stress concentration coefficient is independent of the loading size. When $P_{1}$ is 1,2 , and 3 , the maximum stress is $7.11 \mathrm{MPa}, 14.2 \mathrm{MPa}$, and $21.3 \mathrm{MPa}$, respectively, and the interference coefficients are $1.14 \%, 0.71 \%$, and $0.95 \%$. The interference coefficients are almost equal, indicating that the stress interference intensity between the two holes is almost independent of the applied loading.

3.4. Butterfly-Failure Characteristics of Empty Hole. The scope and distribution of the plastic zone determines the failure pattern and degree of rock mass. In the past, scholars 


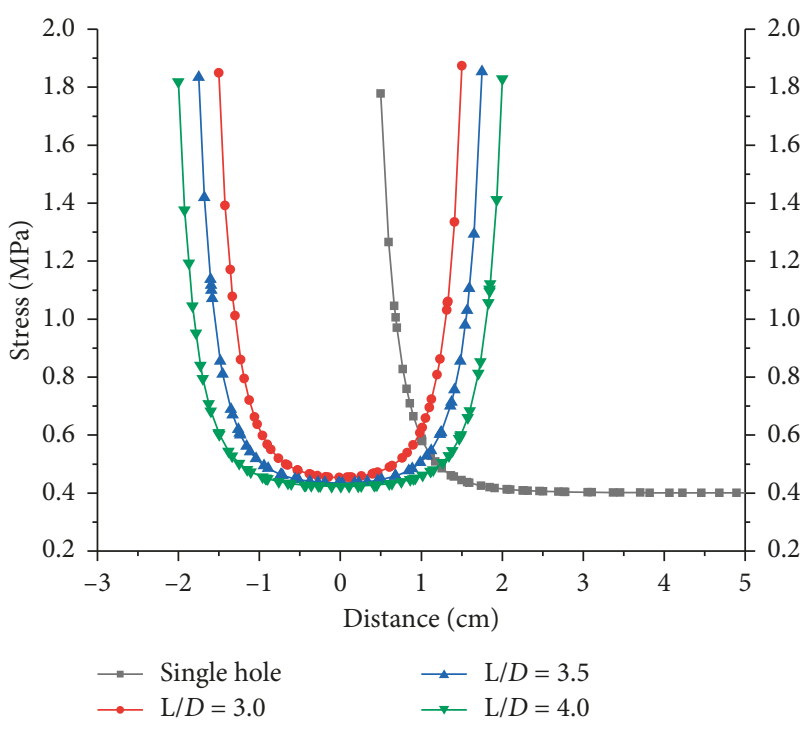

Figure 10: Change curve of the stress when $P_{1}=1 \mathrm{MPa}, \eta=1$, $D=1 \mathrm{~cm}$, and $L$ is $3 D, 3.5 D$, and $4 D$.

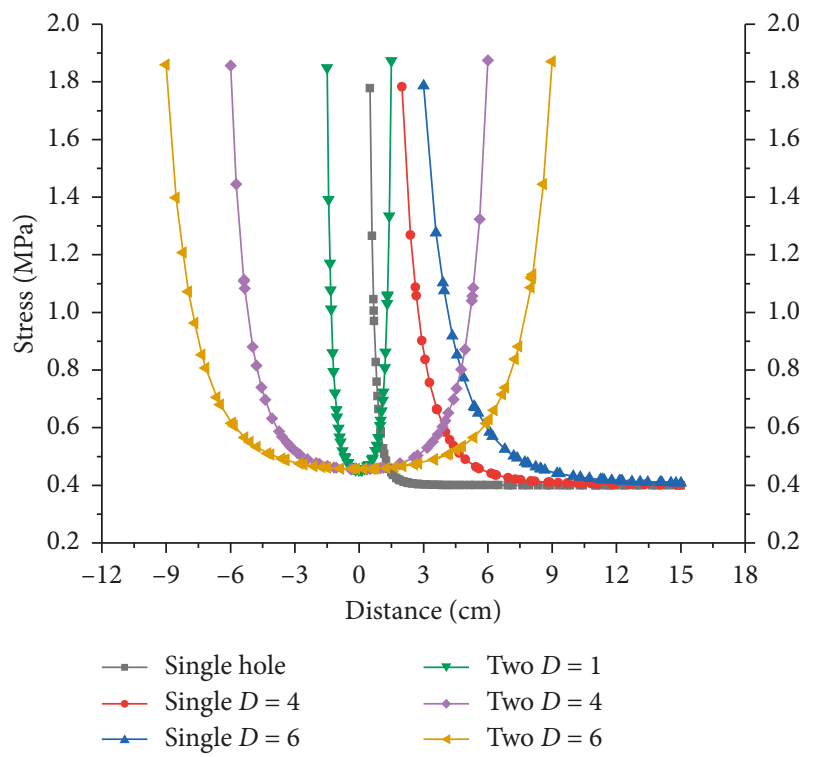

Figure 11: Change curve of the stress when $P_{1}=1 \mathrm{MPa}, \eta=1$, $D=1 \mathrm{~cm}$, and $D$ is $1 \mathrm{~cm}, 4 \mathrm{~cm}$, and $6 \mathrm{~cm}$.

studying the plastic zone of the roadway have arranged the size and position of the roadway reasonably, so as to reduce the plastic failure range of surrounding rock, control the deformation and failure of the roadway, and prevent the occurrence of roof caving and slicing. In contrast to the traditional research, in this paper, plastic failure caused by the formation of empty holes is used to weaken the strength of the roof strata in order to achieve roof cutting and roadway retaining using leading holes.

Based on the immediate roof of return air laneway 12309 , the effects of borehole diameter, lateral pressure ratio, and hole spacing on the distribution of plastic zone were analyzed. The physical and mechanical parameters of rocks are provided in Table 1. According to the data provided by

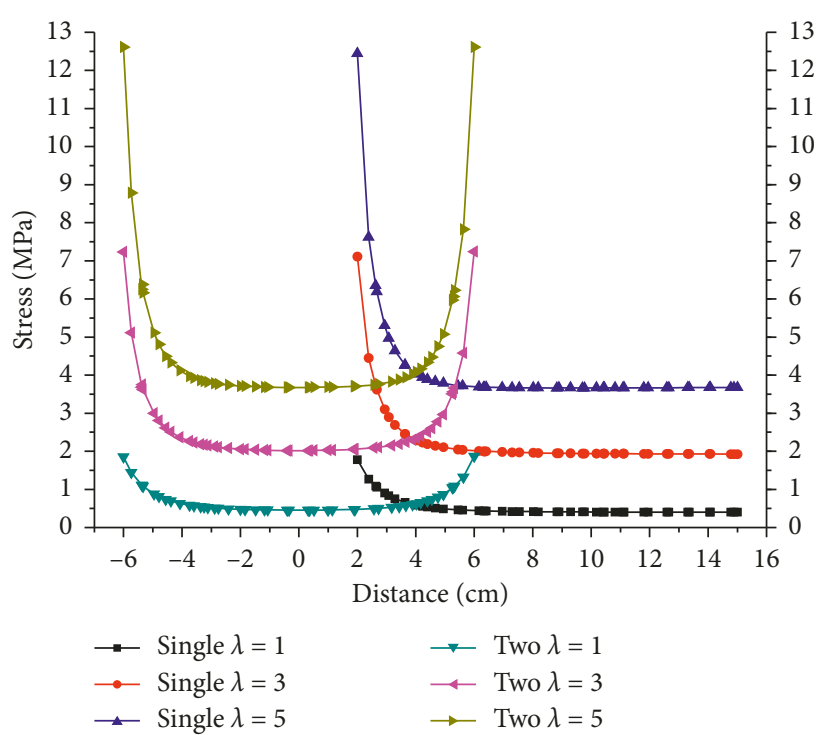

Figure 12: Change curve of the stress when $P_{1}=1 \mathrm{MPa}, D=4 \mathrm{~cm}$, $L / D=3$, and $\eta$ is 1,3 , and 5 .

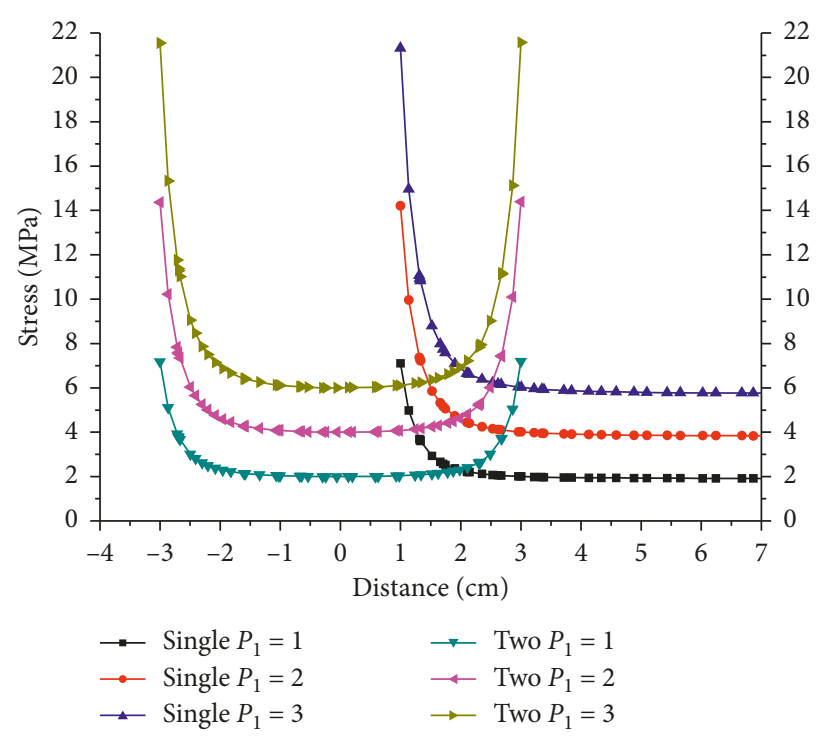

FIgURE 13: Change curve of the stress when $\eta=2, D=4 \mathrm{~cm}, L / D=3$, and $P_{1}$ is 1,2 , and 3 .

the Xiangshan mine, the lateral pressure ratio under this geological condition is 2.3 .

3.4.1. Effect of Pore Diameter on Plastic Failure. This section analyzes the distribution of plastic zones in roof strata with different pore diameters. The simulation scheme is shown in Table 4, and the simulation results are provided in Figure 14.

The failure range of the plastic zone is determined to be positively correlated with pore diameter. With the increase of the pore diameter, the failure pattern of the butterfly shape remains basically unchanged. As the geometric size increases, the four butterfly-failure wings continue to expand away from the hollow area, and the plastic zone near the tip of the butterfly-failure wing increases obviously. 
TABLE 4: Different pore diameter simulation schemes.

\begin{tabular}{|c|c|c|c|c|}
\hline Scheme & $P_{1}(\mathrm{MPa})$ & Lateral pressure ratio $\eta$ & $P_{1}(\mathrm{MPa})$ & Pore diameter $D(\mathrm{~cm})$ \\
\hline 1 & & & & 1.0 \\
\hline 2 & 10 & 23 & 23 & 2.0 \\
\hline 3 & 1.0 & 2.3 & 2.3 & 4.0 \\
\hline 4 & & & & 5.0 \\
\hline
\end{tabular}

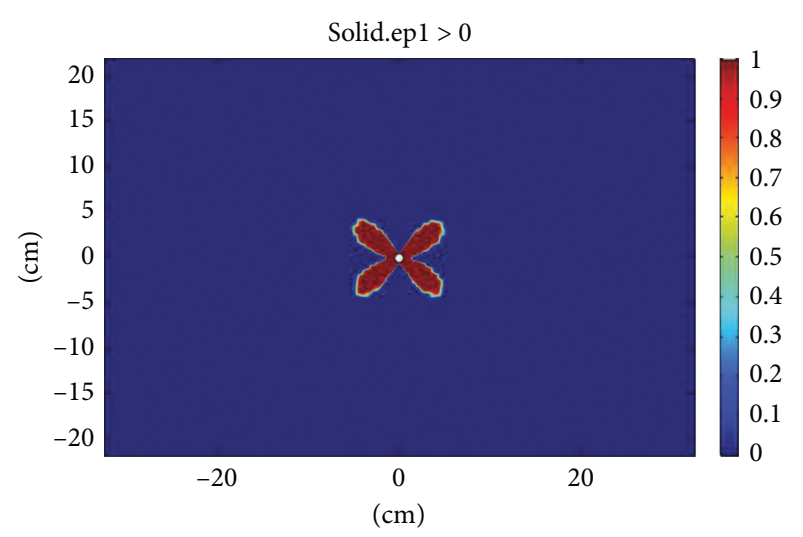

(a)

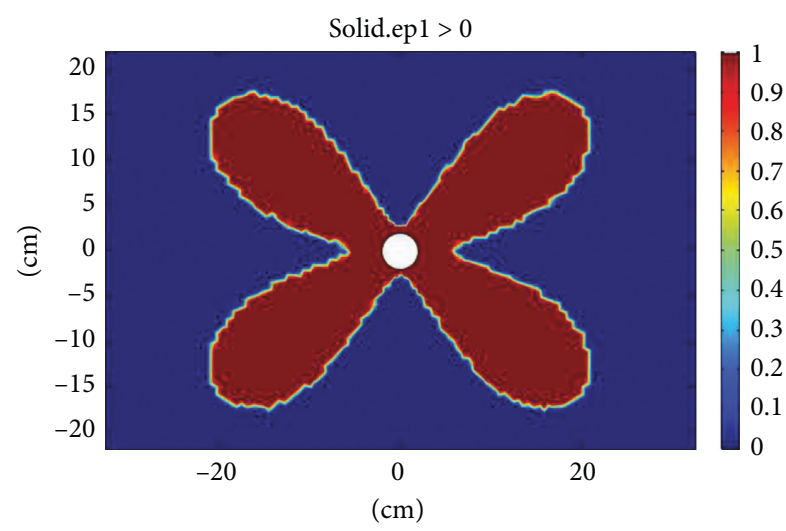

(c)

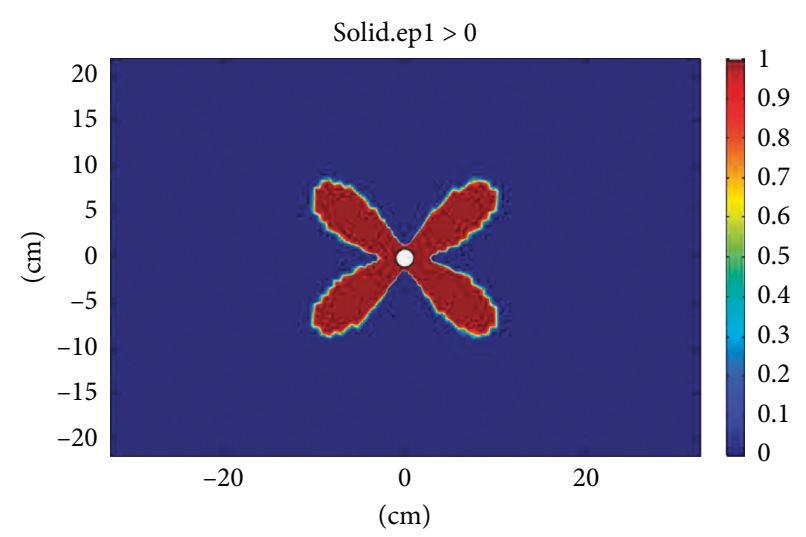

(b)

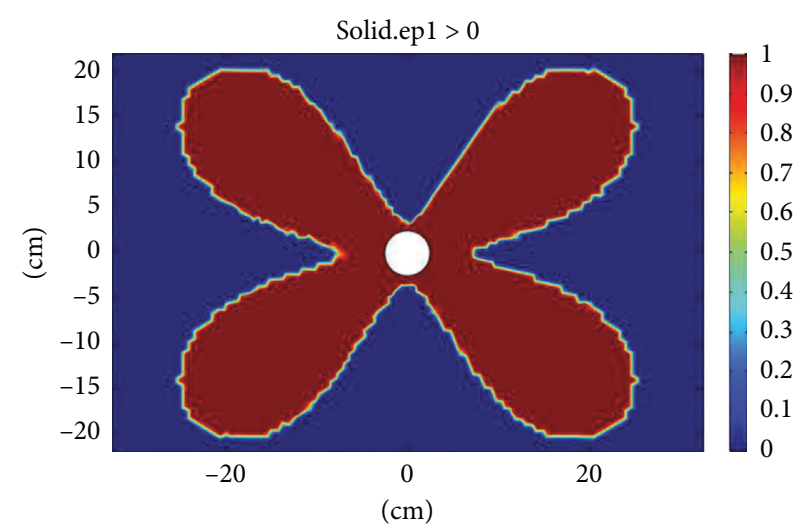

(d)

Figure 14: Distribution of plastic zone with different pore diameters: (a) $D=1.0 \mathrm{~cm}$; (b) $D=2.0 \mathrm{~cm}$; (c) $D=4.0 \mathrm{~cm}$; (d) $D=5.0 \mathrm{~cm}$.

Therefore, the pore diameter will have an impact on the cutting effect. According to the simulation results, a larger pore diameter will lead to greater plastic failure of roof strata, which is more conducive to roof cutting (Figure 15).

3.4.2. Effect of Hole Spacing on Plastic Failure. Butterfly failures occur along the periphery of a single hole after roof drilling. When the roof of the retaining roadway is constructed with multiple boreholes along the advancing direction of the working face, the failure range of the plastic zone can be connected with each other, forming a continuous plastic failure zone in the roof to facilitate the roof cutting. Diameter $D=40 \mathrm{~mm}$ (diameter $D=42 \mathrm{~mm}$ is commonly used in this mine) is used to simulate the plastic distribution of different hole spacing, with the simulation scheme shown in Table 5 and the simulation results shown in Figure 16.
When the hole spacing is $0.3 \mathrm{~m}$, the butterfly-failure zone is distributed widely. The largest part of the butterfly-failure wings produced by single hole is connected with the largest part of the adjacent single hole, which causes the spindle shape failure of the rock mass between the two holes. There is also a small intact rock mass at the connection between the two holes. Compared with the hole spacing of $0.3 \mathrm{~m}$, when the hole spacing is $0.4 \mathrm{~m}$, the distribution range of the butterfly-failure zone is reduced and the distribution range of intact rock mass between the two holes increases. Moreover, the largest part of the butterfly-failure wings produced by single hole is connected with the largest part of the adjacent single hole, and plastic failure zones are connected. When the hole spacing is $0.5 \mathrm{~m}$, the plastic failure zone is obviously reduced, but it can still be interconnected, forming a continuous failure zone in the rock mass. Finally, when the hole spacing is $0.6 \mathrm{~m}$, the butterfly failure caused by single hole is no longer connected and the plastic failure 


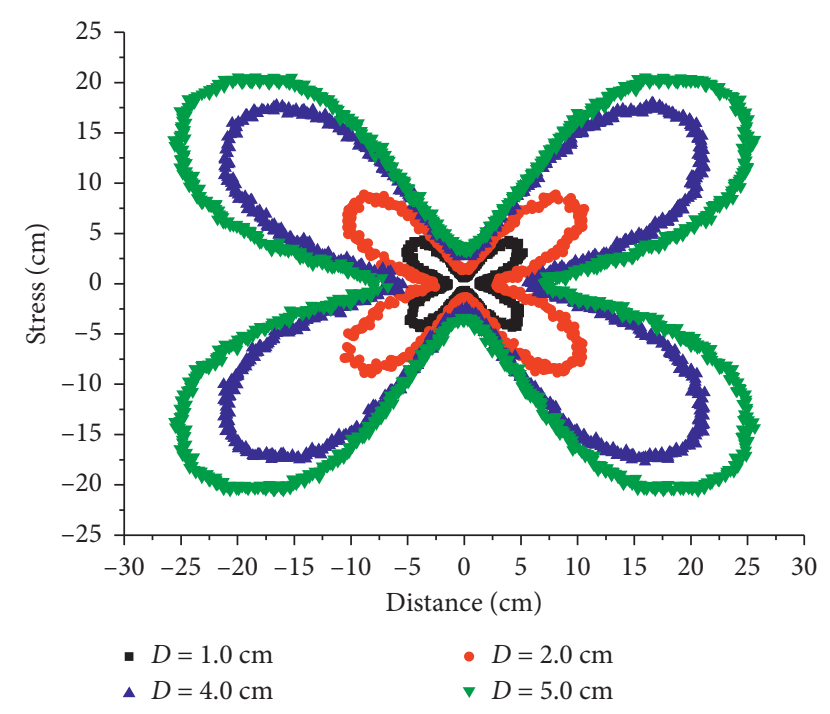

Figure 15: Boundary diagram of plastic zone with different pore diameters.

TABLE 5: Simulation scheme with different hole spacings.

\begin{tabular}{lccccc}
\hline Scheme & $\begin{array}{c}P_{1} \\
(\mathrm{MPa})\end{array}$ & $\eta$ & $\begin{array}{c}P_{1} \\
(\mathrm{MPa})\end{array}$ & $\begin{array}{c}\text { Pore diameter } \\
D(\mathrm{~cm})\end{array}$ & $\begin{array}{c}\text { Hole spacing } \\
L(\mathrm{~m})\end{array}$ \\
\hline 1 & & & & & 0.3 \\
2 & 1.0 & 2.3 & 2.3 & 4 & 0.4 \\
3 & & & & & 0.5 \\
4 & & & & & 0.6 \\
\hline
\end{tabular}

zone is only distributed around each single hole. At this time, the plastic failure cannot form a continuous failure in the rock mass, which is not conducive to roof cutting in gob-side entry retaining.

\section{Industrial Test}

4.1. Construction Technology Design. The auxiliary air roadway in the 21309 fully mechanized working face is the first gob-side entry retaining required for the No. 3 coal working face. The auxiliary air roadway is supported by a combination of "basic support in the roadway (original anchor net support) + strengthened support in the roadway (anchor cable and steel strip) + dynamic pressure temporary strengthened support (single hydraulic prop and $\pi$ steel beam)." When the working face is stoping, empty hole weakening roof is used in the coal wall side of the auxiliary air roadway in the 21309 fully mechanized working face, and dense pillars are used to cut the roof. The coal wall side roof will then collapse along the cutting roof column to form the roadside, releasing pressure and forming the mining roadway of the next working face.

Using directional roof cutting, mine pressure loading from gob roof is cut off. Furthermore, the dislocation separation of roof rock and gob rock is used to realize mining without coal pillar and roadway autogeneration. The periodic roof pressure is also reduced, and the gob-side entry retaining formed by roof cutting and pressure relief mining of dense pillars is realized. The main technological processes of gob-side entry retaining formed by roof cutting and pressure relief mining of dense pillars are as follows: empty hole construction (Figure 17) $\longrightarrow$ anchor cable is used to reinforce the leading roadway $\longrightarrow$ anchor back $\longrightarrow$ cutting coal $\longrightarrow$ single hydraulic prop $+\pi$ steel beam support $\longrightarrow$ blocking gangue supporting in roof cutting roadway $\longrightarrow$ the reinforced supports and $\pi$ steel beam should be removed after the roof is fully caving. The construction technology of cutting roof and retaining roadway is detailed as follows:

(1) Drilling construction: drilling construction is carried out from the gob side of the working face to the auxiliary transport stop line. The drilling operation is completed $50 \mathrm{~m}$ ahead of the working face.

(2) Reinforced anchor cable construction: the reinforced anchor cable is completed from the gob side of the working face to the stop position of the designed retaining roadway. The anchor cable installation is completed $50 \mathrm{~m}$ ahead of the working face.

(3) Temporary strengthening support is then carried out along with temporary dense blocking gangue support, including steel fabric and blocking gangue support.

(4) As the working face is mined, the roof is collapsed and stabilized, the temporary single pillars are withdrawn, and the roadway is finished to meet use requirements.

4.2. Implementation Effect Monitoring. The auxiliary air roadway of 21309 working face was selected as the test object, and the roadway within 400 500 m from the cutting hole was monitored. The station positions are shown in Figure 18, in which the red marks are the measuring points. Six measurement points were set at positions $15 \mathrm{~m}, 30 \mathrm{~m}$, $45 \mathrm{~m}, 60 \mathrm{~m}, 75 \mathrm{~m}$, and $90 \mathrm{~m}$ of the roadway in the experimental section.

4.3. Monitoring Results. The effects of the industrial test for retaining roadway are shown in Figure 19, and the change curve of the observed roof to floor convergence is provided in Figure 20.

Through the analysis of the change of roof and floor convergence at different stations, the following rules are observed:

(1) The change of the roof to floor convergence within a certain distance from the front of the working face can be considered to be caused by the leading support pressure. According to the observation results of six stations, the influence area of leading mining is about $20 \sim 28 \mathrm{~m}$, with an average of $25 \mathrm{~m}$. In the process of advancing the working face to the six measurement points, the roof to floor convergence was $43 \mathrm{~mm}, 58 \mathrm{~mm}, 20 \mathrm{~mm}, 90 \mathrm{~mm}, 25 \mathrm{~mm}$, and $53 \mathrm{~mm}$, respectively, with an average of $48 \mathrm{~mm}$. After the working face pushed through the measurement points, the roof to floor convergence was $349 \mathrm{~mm}$, 


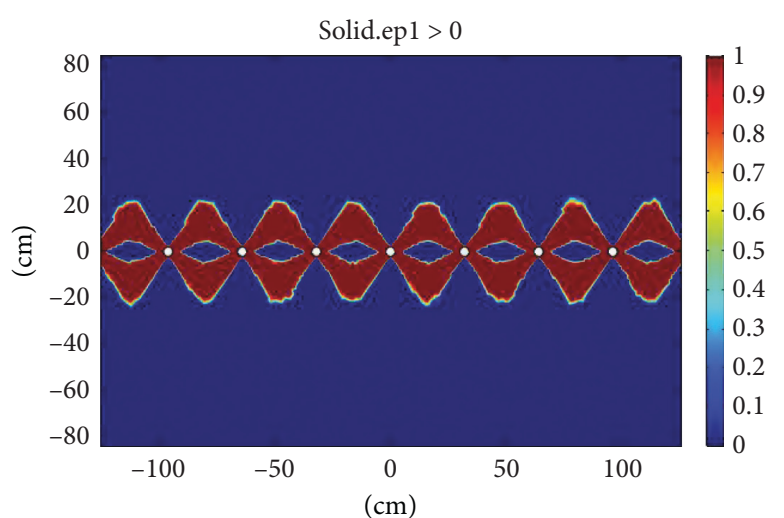

(a)

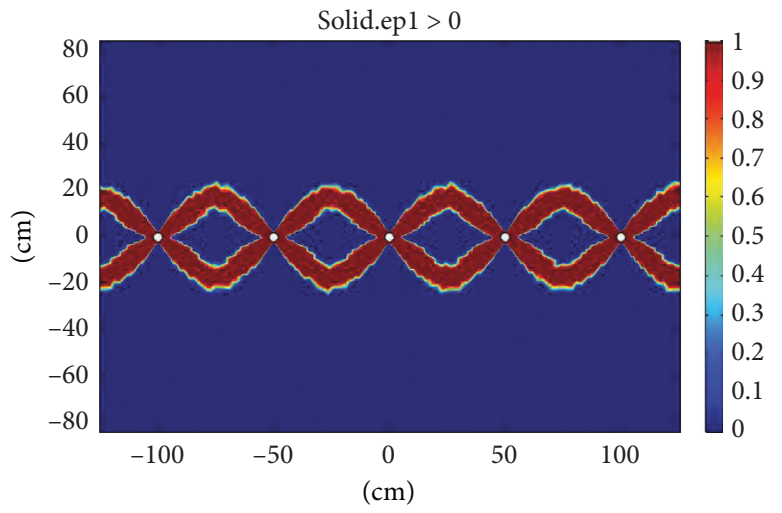

(c)

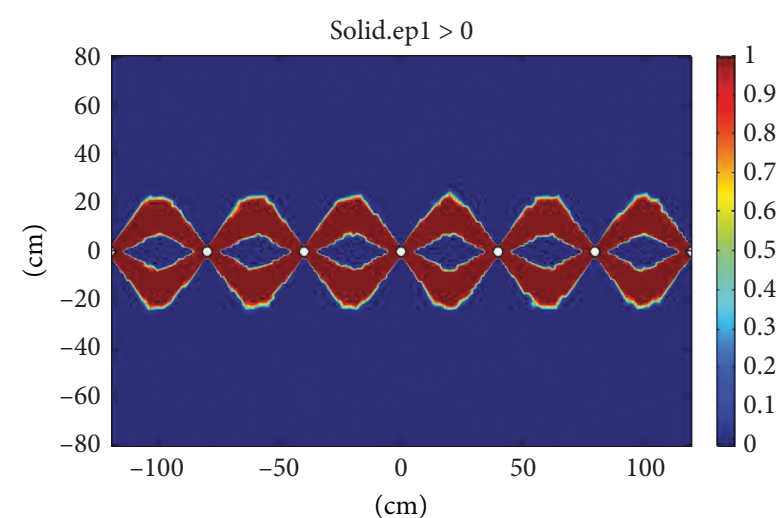

(b)

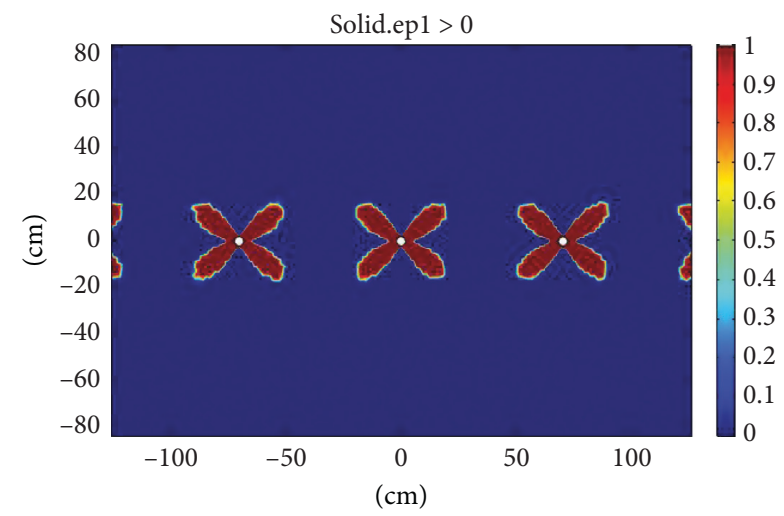

(d)

Figure 16: Plastic zone distribution with different pore diameters: (a) $L=0.3 \mathrm{~m}$; (b) $L=0.4 \mathrm{~m}$; (c) $L=0.5 \mathrm{~m}$; (d) $L=0.6 \mathrm{~m}$.

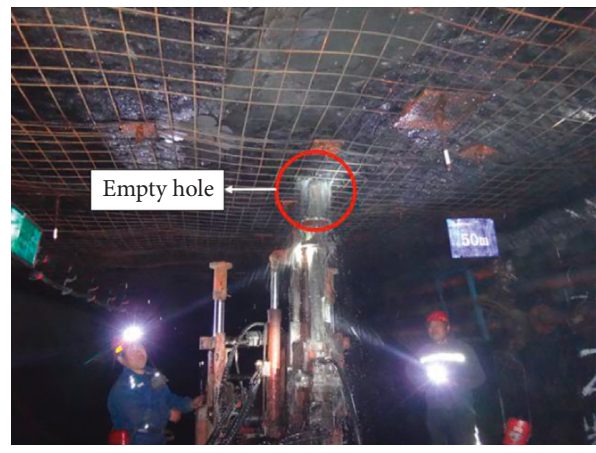

(a)

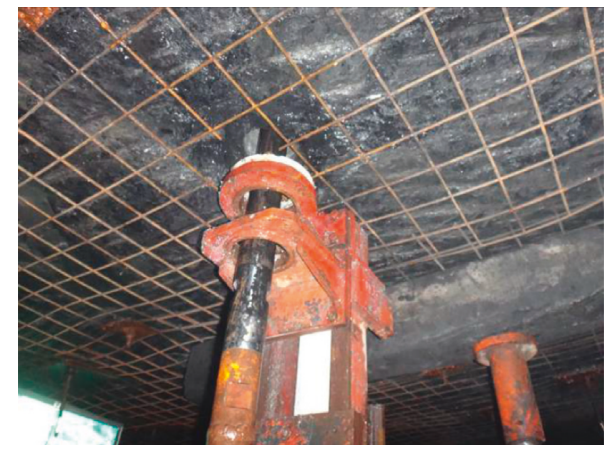

(b)

FiguRe 17: Underground empty hole construction.

$291 \mathrm{~mm}, 302 \mathrm{~mm}, 336 \mathrm{~mm}, 251 \mathrm{~mm}$, and $338 \mathrm{~mm}$, respectively, with an average of $311 \mathrm{~mm}$. It can be seen that the roof rock of the roadway has undergone severe deformation and damage after the working face pushed through, and the surrounding rock deformation of the roadway is predominantly concentrated at this stage.

(2) After roof cutting and roadway retaining, there are three stages in the deformation of the roof and floor. The first stage occurred within $60 \mathrm{~m}$ of the frame. This section was close to the working face and the old roof sunk due to mining. Particularly at $10 \mathrm{~m} \sim 40 \mathrm{~m}$ behind the end frame, the roof and floor were observed to obviously move closer, indicating that the roof is affected by a large pressure. The second stage occurred at $60 \mathrm{~m} \sim 100 \mathrm{~m}$ behind the frame, where the roof was still not completely stable. This area continues to be affected by dynamic pressure in the process of gangue compaction, but the growth rate is slower than that in the first stage. The third stage occurred $100 \mathrm{~m}$ after the frame, in which the gangues were compacted, the active support, passive support, and roof pressure reached a state of balance, and the roof and floor were no longer deformed. 


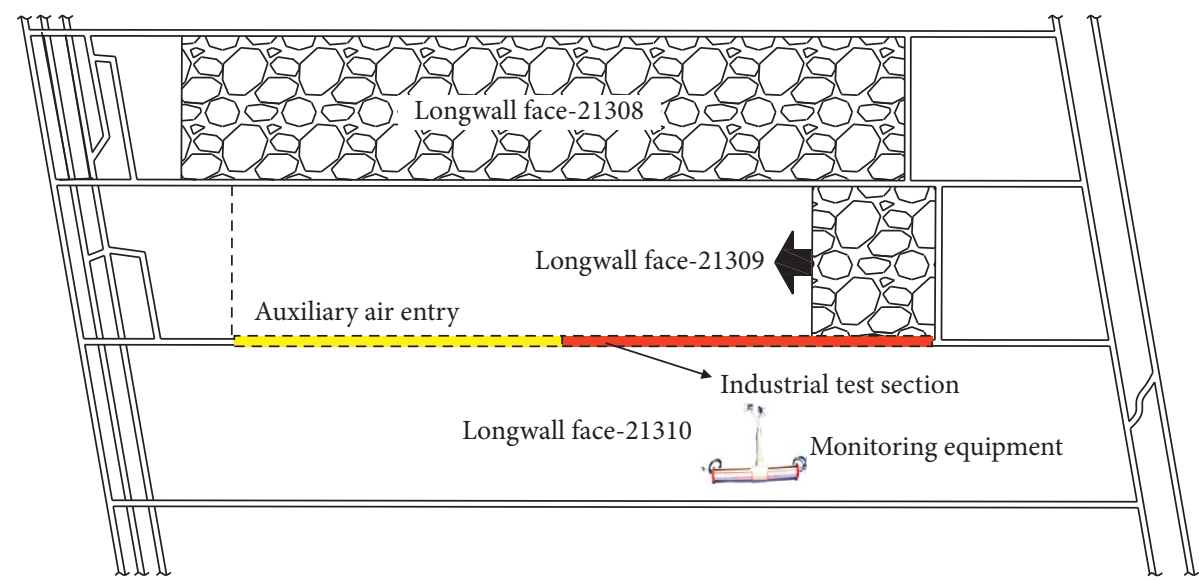

FIGURE 18: Roadway layout of experimental section.

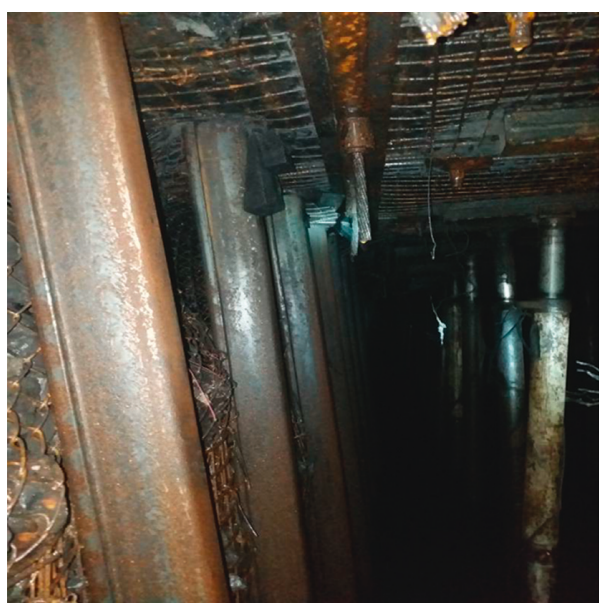

FIgURE 19: Successful retaining of roadway.

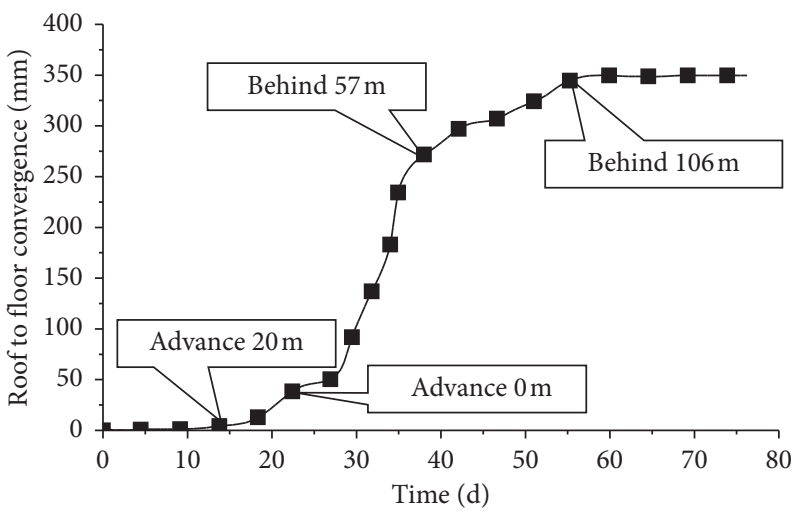

(a)

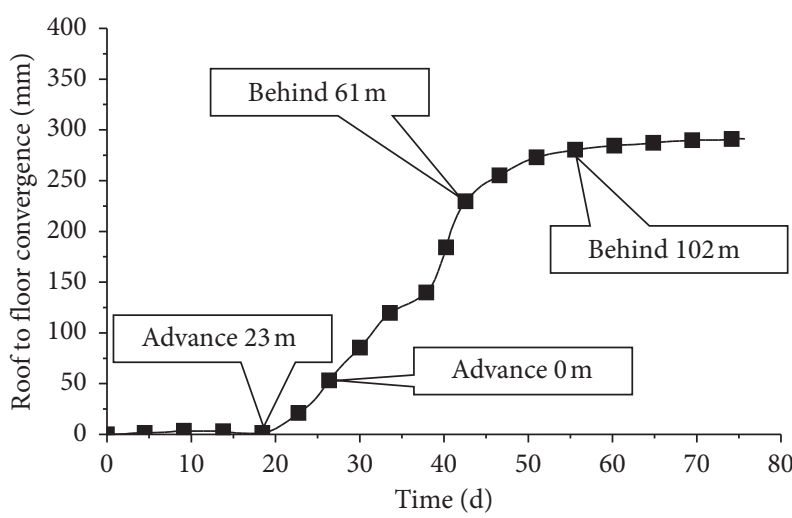

(b)

Figure 20: Continued. 


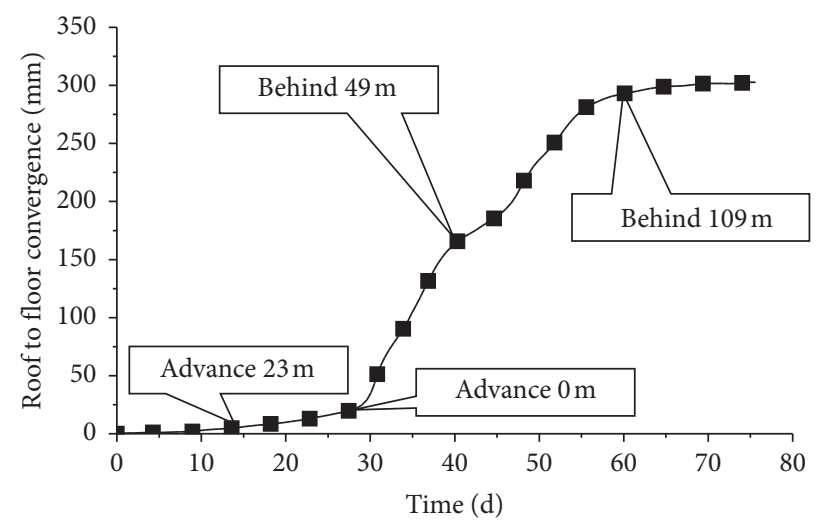

(c)

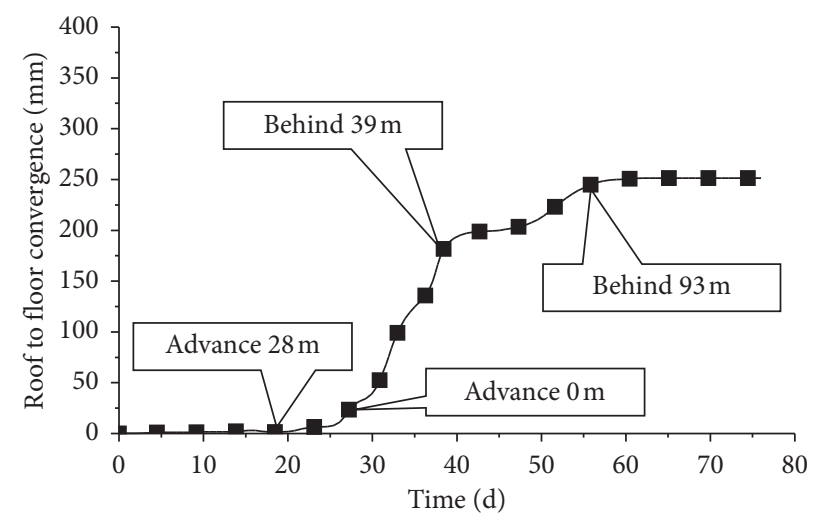

(e)

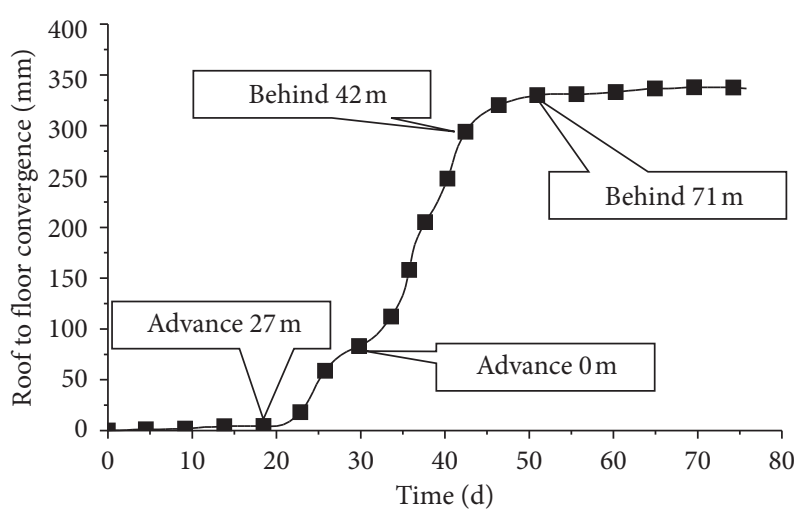

(d)

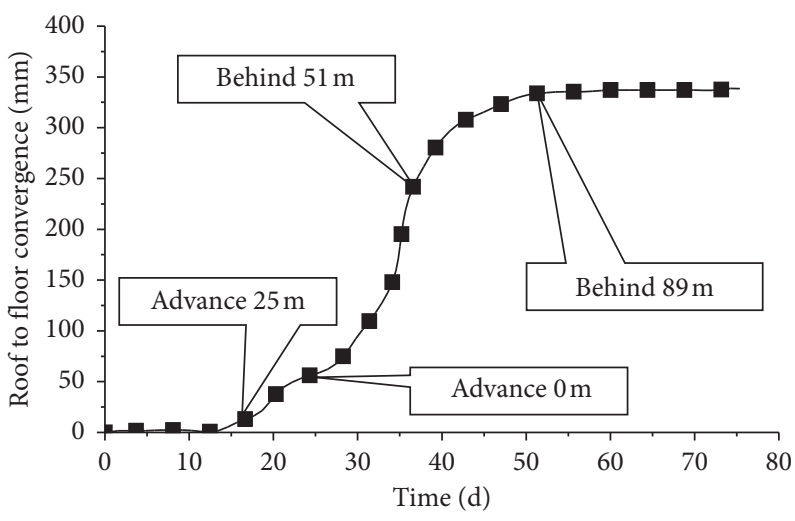

(f)

FiguRE 20: Change curve of the observed roof to floor convergence: (a) No. 1 measurement point; (b) No. 2 measurement point; (c) No. 3 measurement point; (d) No. 4 measurement point; (e) No. 5 measurement point; (f) No. 6 measurement point.

(3) The leading weakening hole replaces the original blasting and cutting technology, omits the blasting and cutting links in the existing gob-side entry retaining technology, that is, omits the charging, assembly line, initiation, dust reduction, danger removal, and other processes. It reduces the cost of retaining the roadway, shortens the time of retaining the roadway, solves the problems of high concentration of coal dust and bad construction environment in the process of blasting, and provides a scientific theoretical basis for the technology of retaining the roadway along the goaf without blasting under such geological conditions.

\section{Conclusions}

(1) The influence of hole spacing and pore diameter on the stress distribution between the two holes was analyzed by COMSOL numerical simulation software. The simulation results are as follows. (1) Under bidirectional unequal pressure, a high stress zone and low stress zone exists around the round holes. (2) When the hole spacing is larger than four times the pore diameter, the stress superposition between the two holes is no longer obvious. (3) The pore diameter is positively correlated with the stress concentration, but not with the stress superposition between the two holes. (4) According to the analysis of the influence of lateral pressure ratio on the stress interference between the two holes, when the lateral pressure ratio is 1 , the stress superposition interference between the two holes is obviously stronger than that under bidirectional unequal pressure. (5) The stress concentration in single hole and the stress superposition interference between two holes are independent of the applied loading.

(2) The distribution of plastic zone in roof rock after drilling was simulated, and the failure characteristics of rock mass around the borehole were analyzed. It is thus concluded that butterfly failure occurs after drilling the roof of the gob. Under bidirectional equal pressure, the plastic zone around the round hole is circular and has a small range. With the increase of the lateral pressure ratio, the shape of plastic zone will gradually change from circular to elliptical and eventually to butterfly. The area of this butterfly plastic zone is positively correlated with the lateral pressure ratio, which is mainly caused by the promotion of four butterfly-failure wings. The simulation results show that with the hole spacing $L \leq 0.5 \mathrm{~m}$, the butterfly-shaped plastic zone between the two holes can be broken through, resulting in continuous 
plastic failure and the formation of a weakening zone inside the strata. With hole spacing $L \geq 0.6 \mathrm{~m}$, the plastic failure zones between the boreholes are independent of each other and cannot be broken through, and the weakening zone of continuous failure cannot be formed inside the strata.

(3) Industrial testing of "empty hole weakening + dense pillar" roof cutting and gob-side entry retaining was carried out in an experimental mine. According to the observation results, nonblasting roof cutting and gob-side entry retaining were successfully carried out. Under this geological condition, the influence range of the advance supporting pressure of the working face is about $25 \mathrm{~m}$. Under the effect of the advance supporting pressure, the surrounding rock of the roadway is slightly deformed, and the stress of the anchor cable is also slightly increased. During the process of retaining the roadway along the goaf, the deformation and failure of the surrounding rock of the roadway will go through three stages. In the early stage of the roadway cutting, the deformation rate of the surrounding rock is large, the roof and floor of the roadway are gradually close to the two sides of the rock, and the anchor cable is also slightly increased The cable stress increases significantly, and this stage is mainly located within $20-60 \mathrm{~m}$ behind the frame; the roof is successfully cut backward, and the surrounding rock of the roadway does not stop deformation rapidly, but it deforms at a smaller rate because before the collapsed gangue is fully compacted, the remaining roof and the surrounding rock of the roadway are still subject to the force generated by the overlying strata, and this stage is generally located within 30-100 $\mathrm{m}$ behind the frame When the gangue in the goaf is fully compacted, the roadway will enter a stable stage, in which the surrounding rock of the roadway will hardly deform.

\section{Data Availability}

All data generated or analyzed during this study are included in this article.

\section{Conflicts of Interest}

The authors declare no conflicts of interest.

\section{Authors' Contributions}

T. Y. and J. Z. conceived and designed the experiments and T. Y. wrote the paper.

\section{Acknowledgments}

This study was supported by the National Natural Science Foundation of China (nos. 5147173 and 51774229), Shaanxi Innovation Capability Support Plan-Science and Technology Innovation Team Project (2018TD-038), and Shaanxi Natural Science Basic Research Plan (Shaanxi Coal Joint Fund)
Project (2019JLM-41). The funding of the agencies is gratefully acknowledged.

\section{References}

[1] M. He, Y. Gao, J. Yang, and W. Gong, "An innovative approach for gob-side entry retaining in thick coal seam longwall mining," Energies, vol. 10, no. 11, p. 1785, 2017.

[2] R. Wu, Q. He, J. Oh, Z. Li, and C. Zhang, "A new gob-side entry layout method for two-entry longwall systems," Energies, vol. 11, no. 8, p. 2084, 2018.

[3] D. Fan, X. Liu, Y. Tan et al., "Roof cutting parameters design for gob-side entry in deep coal mine: a case study," Energies, vol. 12, no. 10, p. 2032, 2019.

[4] X. Ma, M. He, J. Wang, Y. Gao, D. Zhu, and Y. Liu, "Mine strata pressure characteristics and mechanisms in gob-side entry retention by roof cutting under medium-thick coal seam and compound roof conditions," Energies, vol. 11, no. 10, p. 2539, 2018.

[5] C. Han, N. Zhang, J. Xue, J. Kan, and Y. Zhao, "Multiple and long-term disturbance of gob-side entry retaining by grouped roof collapse and an innovative adaptive technology," Rock Mechanics and Rock Engineering, vol. 52, no. 8, pp. 2761-2773, 2019.

[6] G. R. Feng, P. F. Wang, and Y. P. Chugh, "A new gob-side entry layout for longwall top coal caving," Energies, vol. 11, p. 1192, 2018.

[7] L. Wang, H.-Y. Cheng, and H. Y. Liu, "An analysis of fatal gas accidents in Chinese coal mines," Safety Science, vol. 62, pp. 107-113, 2014.

[8] E. Z. Zhen, Y. J. Wang, J. Yang, and M. C. He, "Comparison of the macroscopical stress field distribution characteristics between a novel non-pillar mining technique and two other current methods," Advances in Mechanical Engineering, vol. 11, no. 5, 2019.

[9] Q. Zhang, J. Zhang, Z. Wu, and Y. Chen, "Overview of solid backfilling technology based on coal-waste underground separation in China," Sustainability, vol. 11, no. 7, p. 2118, 2019.

[10] Y. Ren, G. Feng, P. Wang et al., "Vertical stress and deformation characteristics of roadside backfilling body in gob-side entry for thick coal seams with different pre-split angles," Energies, vol. 12, no. 7, p. 1316, 2019.

[11] Z. Zhang, X. Yu, H. Wu, and M. Deng, "Stability control for gob-side entry retaining with supercritical retained entry width in thick coal seam longwall mining," Energies, vol. 12, no. 7, p. 1375, 2019.

[12] X. Li, N. Zhang, Z. Xie, D. Liang, and Y. Zhao, "Study on efficient utilization technology of coal pillar based on gob-side entry driving in a coal mine with great depth and high production," Sustainability, vol. 11, no. 6, p. 1706, 2019.

[13] J. Hu, M. He, J. Wang, Z. Ma, Y. Wang, and X. Zhang, "Key parameters of roof cutting of gob-side entry retaining in a deep inclined thick coal seam with hard roof," Energies, vol. 12, no. 5, p. 934, 2019.

[14] M. He, X. Ma, and B. Yu, "Analysis of strata behavior process characteristics of gob-side entry retaining with roof cutting and pressure releasing based on composite roof structure," Shock and Vibration, vol. 2019, Article ID 2380342, 12 pages, 2019.

[15] Z. Guo, Q. Wang, Z. Li et al., "Surrounding rock control of an innovative gob-side entry retaining with energy-absorbing supporting in deep mining," International Journal of LowCarbon Technologies, vol. 14, no. 1, pp. 23-35, 2019. 
[16] W. Qiao, H. Lu, G. Zhou, M. Azimi, Q. Yang, and W. Tian, “A hybrid algorithm for carbon dioxide emissions forecasting based on improved lion swarm optimizer," Journal of Cleaner Production, vol. 244, p. 118612, 2020.

[17] W. Qiao, Z. Yang, Z. Kang, and Z. Pan, "Short-term natural gas consumption prediction based on volterra adaptive filter and improved whale optimization algorithm," Engineering Applications of Artificial Intelligence, vol. 87, Article ID 103323, 2020.

[18] W. Qiao and Z. Yang, "An improved dolphin swarm algorithm based on Kernel Fuzzy C-means in the application of solving the optimal problems of large-scale function," IEEE Access, vol. 8, pp. 2073-2089, 2019.

[19] W. Qiao and Z. Yang, "Forecast the electricity price of U.S. using a wavelet transform-based hybrid model," Energy, vol. 193, Article ID 116704, 2020.

[20] W. Qiao and Z. Yang, "Solving large-scale function optimization problem by using a new metaheuristic algorithm based on quantum dolphin swarm algorithm," IEEE Access, vol. 7, pp. 138972-138989, 2019.

[21] W. Qiao, W. Tian, Y. Tian, Q. Yang, Y. Wang, and J. Zhang, "The forecasting of PM2.5 using a hybrid model based on wavelet transform and an improved deep learning algorithm," IEEE Access, vol. 7, pp. 142814-142825, 2019.

[22] W. Qiao and Z. Yang, "Modified dolphin swarm algorithm based on chaotic maps for solving high-dimensional function optimization problems," IEEE Access, vol. 7, pp. 110472110486, 2019.

[23] W. Qiao, K. Huang, M. Azimi, and S. Han, "A novel hybrid prediction model for hourly gas consumption in supply side based on improved whale optimization algorithm and relevance vector machine," IEEE Access, vol. 7, pp. 88218-88230, 2019.

[24] Y. Chen, S. Ma, and Q. Cao, "Extraction of the remnant coal pillar in regular and irregular shapes: a case study," Journal of Loss Prevention in the Process Industries, vol. 55, pp. 191-203, 2018.

[25] X. S. Liu, J. G. Ning, Y. L. Tan, Q. Xu, and D. Y. Fan, "Coordinated supporting method of gob-side entry retaining in coal mines and a case study with hard roof," Geomechanics and Engineering, vol. 15, pp. 1173-1182, 2018.

[26] G. C. Zhang, Y. L. Tan, S. J. Liang, and H. G. Jia, "Numerical estimation of suitable gob-side filling wall width in a highly gassy longwall mining panel," International Journal of Geomechanics, vol. 18, no. 8, Article ID 04018091, 2018.

[27] Z. Z. Zhang, W. J. Wang, S. Q. Li et al., "An innovative approach for gob-side entry retaining with thick and hard roof: a case study," Technical Gazette, vol. 25, no. 4, pp. 1028-1036, 2018.

[28] S. Zhang, X. Wang, G. Fan, D. Zhang, and C. Jianbin, "Pillar size optimization design of isolated island panel gob-side entry driving in deep inclined coal seam-case study of pingmei no. 6 coal seam," Journal of Geophysics and Engineering, vol. 15, no. 3, pp. 816-828, 2018.

[29] J. Z. Li, M. Zhang, Y. Li, and H. Hu, "Surrounding rock control mechanism in the gob-side retaining entry in thin coal seams, and its application," Journal of the Southern African Institute of Mining and Metallurgy, vol. 118, no. 5, pp. 471480, 2018.

[30] P. S. Zhang, Z. H. Kan, W. Yan, B. Shen, Y. P. Zhao, and S. X. Wu, "Experimental study on the stability of surrounding soft rocks of gob-side entry retaining in fully mechanized caving," Journal of the Southern African Institute of Mining and Metallurgy, vol. 118, pp. 481-492, 2018.
[31] W. Gao, H. Wu, M. Kamran Siddiqui et al., "Study of biological networks using graph theory," Saudi Journal of Biological Sciences, vol. 25, no. 6, pp. 1212-1219, 2017.

[32] W. Gao, J. L. G. Guirao, B. Basavanagoud, and J. Wu, "Partial multi-dividing ontology learning algorithm," Information Sciences, vol. 467, pp. 35-58, 2018.

[33] W. Gao, J. L. G. Guirao, M. Abdel-Aty, and W. Xi, "An independent set degree condition for fractional critical deleted graphs," Discrete and Continuous Dynamical Systems-Series S, vol. 12 , no. $4-5$, pp. $877-886,2019$.

[34] W. Gao, J. L. G. Guirao, M. Abdel-Aty et al., "An independent set degree condition for fractional critical deleted graphs," Discrete \& Continuous Dynamical Systems-S, vol. 12, no. 4-5, pp. 877-886, 2019.

[35] W. Gao, W. Wang, D. Dimitrov, and Y. Wang, "Nano properties analysis via fourth multiplicative $\mathrm{ABC}$ indicator calculating," Arabian Journal of Chemistry, vol. 11, no. 6, pp. 793-801, 2018.

[36] J. Chen, D. Lu, W. Liu et al., "Stability study and optimization design of small-spacing two-well (SSTW) salt caverns for natural gas storages," Journal of Energy Storage, vol. 27, Article ID 101131, 2020. 


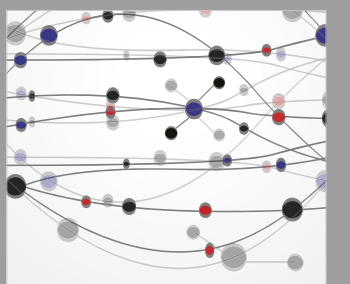

The Scientific World Journal
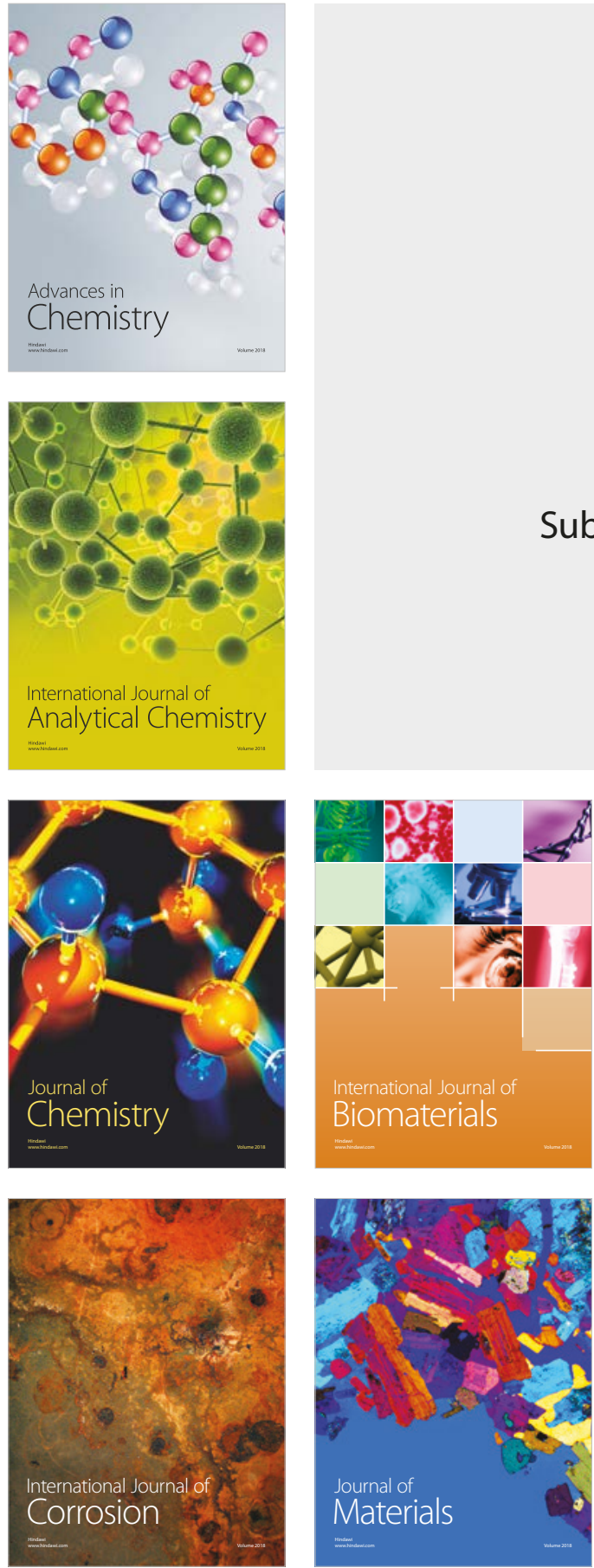

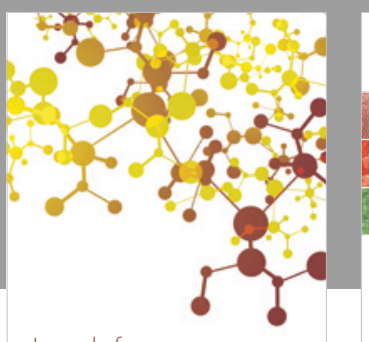

Journal of

Applied Chemistry
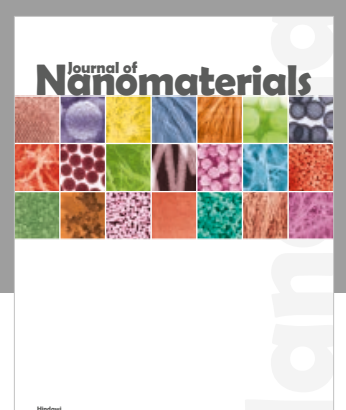

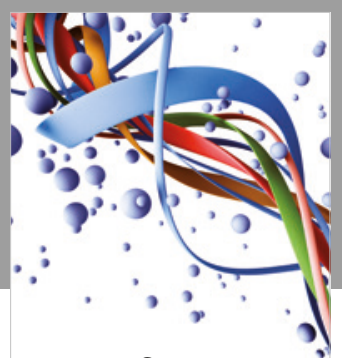

Scientifica

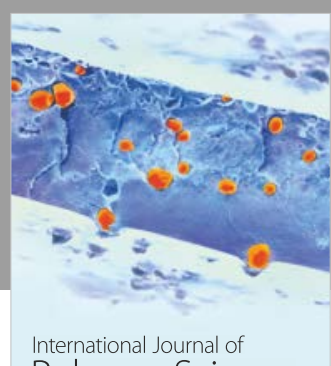

Polymer Science

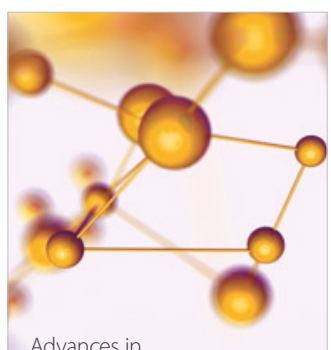

Physical Chemistry
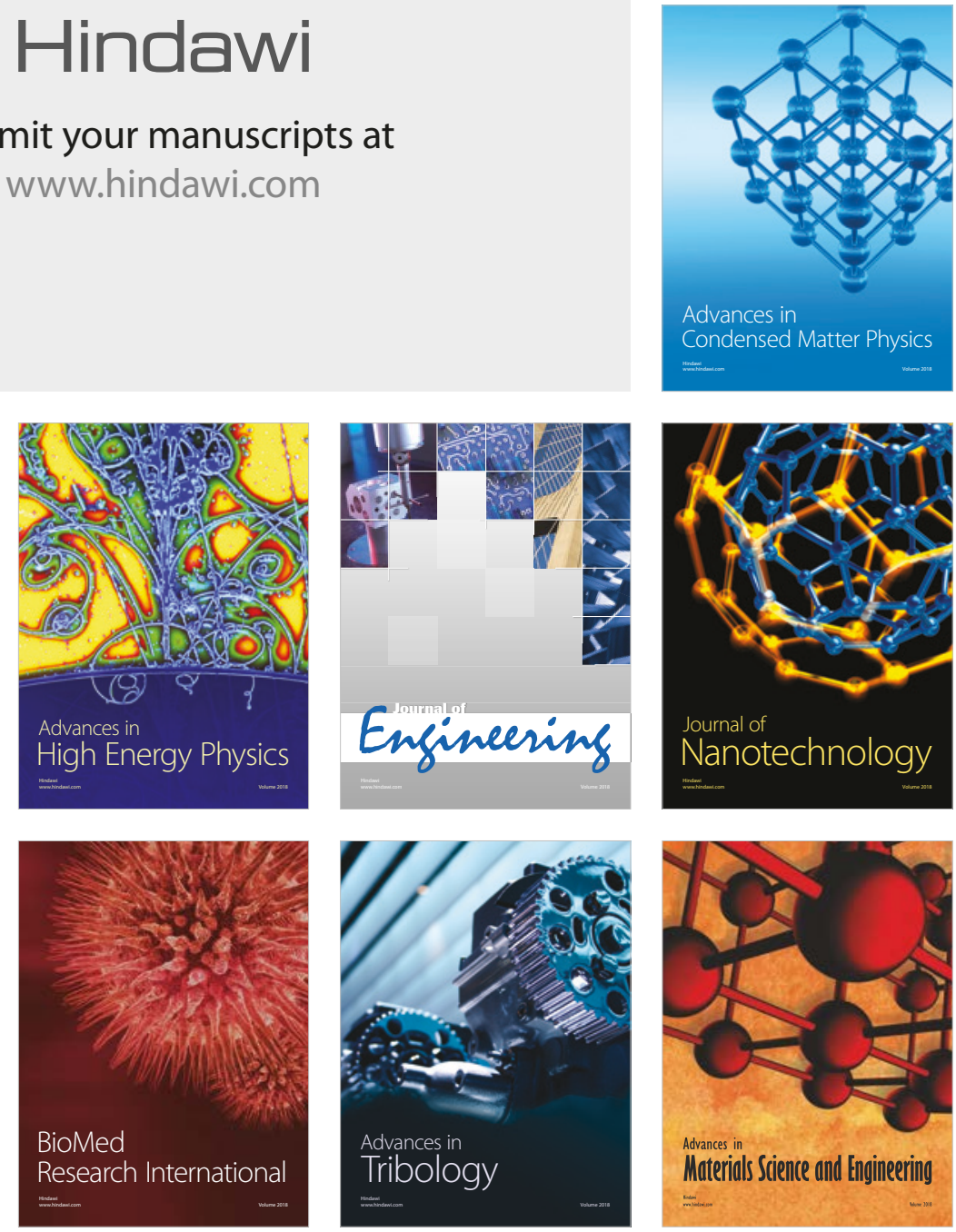